\title{
Measuring Change Over Time in Socio- economic Deprivation and Health in an Urban Context: The Case Study of Genoa
}

\section{Stefano Landi, Enrico Ivaldi \& Angela Testi}

\section{Social Indicators Research}

An International and Interdisciplinary Journal for Quality-of-Life Measurement

ISSN 0303-8300

Soc Indic Res

DOI 10.1007/s11205-017-1720-3

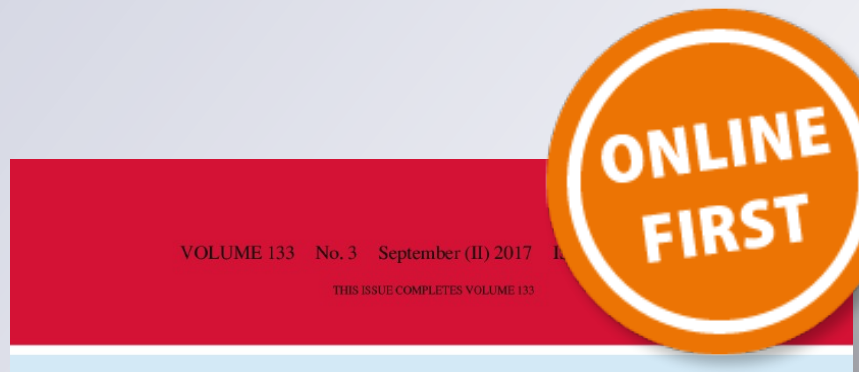

SOC I A L INDICA TORS R E S E A R C H

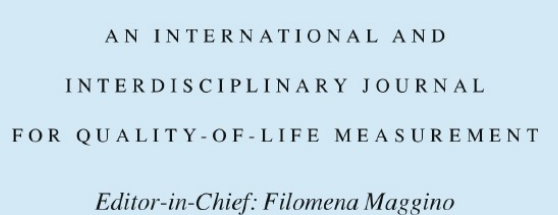

Editor-in-Chief: Filomena Maggino 
Your article is protected by copyright and all rights are held exclusively by Springer Science+Business Media B.V.. This e-offprint is for personal use only and shall not be selfarchived in electronic repositories. If you wish to self-archive your article, please use the accepted manuscript version for posting on your own website. You may further deposit the accepted manuscript version in any repository, provided it is only made publicly available 12 months after official publication or later and provided acknowledgement is given to the original source of publication and a link is inserted to the published article on Springer's website. The link must be accompanied by the following text: "The final publication is available at link.springer.com". 


\title{
Measuring Change Over Time in Socio-economic Deprivation and Health in an Urban Context: The Case Study of Genoa
}

\author{
Stefano Landi ${ }^{1,3}$ (D) Enrico Ivaldi $^{2} \cdot$ Angela Testi $^{1}$
}

(C) Springer Science+Business Media B.V. 2017

\begin{abstract}
The inverse relationship between socioeconomic and health status has been well established in the literature. Disparities in health status due to socioeconomic conditions are unfair and can be prevented through appropriate health and social policies. The relation between socioeconomic factors and health outcomes can be proven at both the individual and geographic level. In this study, we follow the second stream of literature. The objective of the study is to measure how deprivation changes over time in an urban context, finding out whether socioeconomic inequalities association with health outcomes endure over time. To do so, a census-based deprivation index (GDI-Genoa Deprivation Index) have been developed using three aggregation methods-additive, Mazziotta-Pareto, and Pena distance. The innovation of the work is the attempt to evaluate deprivation over time, trying to formalize a methodological path replicable in other situation. Health status has been assessed using the standardized (premature) mortality ratios. The findings reveal that although deprivation inequalities continue to exist in Genoa, global levels have been decreasing. In addition, the rate of premature mortality has shown improvements. Despite this, GDI scores continue to be associated with premature deaths: individuals living in deprived areas report consistently high standardised mortality ratios.
\end{abstract}

Keywords Deprivation - Health status · Mazziotta-Pareto - Genoa Deprivation Index · Standardized mortality ratios · Deprivation over time $\cdot$ Health inequalities ·

Socioeconomic inequalities

Stefano Landi

stefano.landi@unive.it

1 Department of Economics and Business Studies, University of Genoa, Genoa, Italy

2 Department of Political Science, University of Genoa, Genoa, Italy

3 Department of Management, University "Ca' Foscari” Venice, Fondamenta, S. Giobbe, 873, 30121 Venice, Italy 


\section{Introduction}

Several studies have addressed the inverse relationship between socioeconomic status and the incidence of most diseases. In many European countries, higher morbidity and mortality rates have been reported among lower socioeconomic groups (Andersen et al. 2014; Boarini and Mira d'Ercole 2006; Bond Huie et al. 2003; Boyle et al. 1999; Deaton and Lubotsky 2003; Mackenbach et al. 2003; Regidor et al. 2005; Strand et al. 2010; Stringhini et al. 2010). Health inequalities can be attributed to the differing circumstances in which people grow, live, work, and age. Therefore, from an economic and policy viewpoint, health status depends on not only resources devoted to healthcare but also those assigned to lifestyle and education and general socioeconomic conditions. Health status differences arising from socioeconomic conditions are considered unfair and can be avoided by employing active social policies (Adler and Newman 2002; Mackenbach et al. 2003; Mackenbach 2010, 2012; Testi and Ivaldi 2009). The relationship between socioeconomic factors and health outcomes has been proven at both the individual (Andersen et al. 2014; Jackson et al. 2014; Van Doorslaer 1997) and the geographic level (Hoffmann et al. 2014; Jarman 1983; Mackenbach et al. 2008) level.

This study adopts the second approach in which deprivation indexes are generally implemented as an instrument to assess socioeconomic inequalities. Townsend (1987) defines deprivation as 'a state of observable and demonstrable disadvantage relative to the local community or the wider society or nation to which an individual, family or group belongs', thus indicating a phenomenon wider than poverty. In fact, in addition to resources owned, for example, income or its proxies, deprivation refers to an individual's capability to fully participate in society (Sen 1987).

A variety of indexes have been implemented to identify deprivation (Allik et al. 2016; Atkinson et al. 2014; Bell and Hayes 2012; Caranci et al. 2010; Cadum et al. 1999; Havard et al. 2008; Lalloué et al. 2013; Noble et al. 2010; Panczak et al. 2012; Petrelli et al. 2006). They comprise a set of variables, each representing a dimension of deprivation, combined into a single index score. The most used input variables to build a deprivation index are for example unemployment (Haynes et al. 1996), no car access, lack of home ownership, low social class, and household overcrowding (Senior 2002). Deprivation indexes are quite simple, inexpensive instruments adopted to measure the socioeconomic conditions of residence areas because they include census indicators, which are easily available and combined using various statistical procedures. Deprivation indexes were developed in the United Kingdom (Carstairs and Morris 1991; Forrest and Gordon 1993; Townsend 1987) to measure general practitioner workload, capitation, and health inequalities. Today, the indexes are applied in numerous other countries to, for example, measure the correlation between deprivation and mortality (Benach and Yasui 1999; Bond Huie et al. 2003; Hoffmann et al. 2014; Lalloué et al. 2013; Santana et al. 2015; Stringhini et al. 2010) or incidence of specific diseases (Andersen et al. 2014; Jackson et al. 2014; Petrelli et al. 2006; Smits et al. 2002; Spadea et al. 2010; Su et al. 2016). In addition, deprivation indexes have been used to demonstrate the relationship between lifestyle and socioeconomic status (Burrows et al. 2010; Gotsens et al. 2013; Kelleher et al. 2002).

Studies have shown that areas with lower deprivation levels report a better health status, such as greater improvements in infant mortality and cancer survival (Basta et al. 2014; Norman et al. 2008), and those at a persistent disadvantage show the worst self-reported health and mortality outcomes (Boyle et al. 2009; Exeter et al. 2011; Norman 2010). Thus, it is useful to determine whether deprivation levels have changed 
in geographic areas over time and assess if changes in deprivation level impact health. A study closely related to ours is that of Ivaldi and Testi (2011), who proposed the Genoa Deprivation Index (GDI) to measure material deprivation in an urban context using data from the 1991 and 2001 Italian censuses. Their results revealed the presence of socioeconomic inequalities in the Genoa city wards, which were correlated to health inequalities in mortality (Ivaldi and Testi 2011). Similarly, this study aims to measure how deprivation in an urban context has changed over time and determine if socioeconomic inequalities continue to be associated over time with health outcomes in the city of Genoa. To do so, we propose a method to evaluate deprivation changes during 1991-2011. The introduced methodological path can be replicated in other situations and is the main novelty of our analysis.

The remainder of this study is structured as follows. Section 2 presents the methodological path adopted in this study. More specifically, it first introduces the approaches used to measure deprivation levels and health outcomes, followed by a framework setup to compare deprivation over time. Section 3 provides the results and Sect. 4 discusses them in line with the extant literature and the practical application of our approach. Section 5 concludes.

\section{Materials and Methods}

Before attempting to understand the relationship between health outcomes and socioeconomic conditions in urban areas and analyse changes in over time, it is necessary to address the various methodological challenges. The steps are the following: measurement of deprivation, assessment of health status, comparison of the relationship between the two domains, and finally, estimations of changes over time.

\subsection{Small area Deprivation Index}

This study references research that adopts small area deprivation indexes, beginning with the seminal work by Jarman (1983). The deprivation indexes are defined in the context of small, well-specified geographical areas, where 'the proportion of households...with a combination of circumstances indicating low living standards, or a high need for services, or both' is measured (Bartley and Blane 1994). Therefore, it is necessary to define (1) the input variables that can be used to measure deprivation, (2) the geographical scale, and (3) the methods to combine the variables into an index.

First, the input variables used to measure deprivation are house ownership, unemployment rate, low education level, and household overcrowding (Table 1), which are

Table 1 Deprivation indicators in GDI (Italian census data 1991, 2001, and 2011)

\begin{tabular}{ll}
\hline Indicator & Definition \\
\hline House ownership & $\%$ of households living in rented houses \\
Unemployment rate & $\%$ of unemployed people compared to total workforce \\
Low education level & $\%$ of people with a degree lower or equal to middle school diploma \\
Household overcrowding & Average number of occupants per room \\
\hline
\end{tabular}


included in the GDI (Ivaldi and Testi 2011). These variables describe socioeconomic status at various levels and can be considered direct variables to create, what Townsend (1987) calls, a 'material' indicator of deprivation. Unemployment denotes a state of economic insecurity and lack of resources; house ownership is a proxy for wealth and reduced housing quality with possible negative effects on physical and mental well-being; and low education level is used for its potential capacity to provide information on current income. However, GDI differs from the Towsend index because it includes education level rather than car ownership as an indicator. The list of included variable in GDI is motivated by the results of factorial analyses, performed on all census variables utilised in the most common deprivation indexes proposed by the literature (Ivaldi and Testi 2011). In this work the indicators are computed using data from Italian censuses conducted in 1991, 2001, and 2011 (Appendix 1).

Second, the choice of geographical scale is important; because the use of measures based on geographic areas rather than individual conditions causes the implicit assumption of equality among people living in the same area. Therefore, it is important to interpret results while considering the risk of ecological fallacy ['not all deprived individuals live in deprived wards, just as not everybody in a ward ranked as deprived are deprived themselves' (Townsend et al. 1988)]. Although a relevant issue, it is difficult to obtain individual deprivation measures and both individual- and area-level deprivation are important determinants of health status (Hagedoorn et al. 2016; Spadea et al. 2010). Thus, small area indexes should identify 'environmental' components underlying social differences as a proxy for unknown individual characteristics. The validity of an environmental effect is generally assumed for territories defined as 'small areas'. However, this definition is not entirely unambiguous. In the United Kingdom, deprivation is commonly calculated using electoral wards (e.g. 'pseudo-postcode sector' in Scotland) that comprise about 2000 households, although proposals have been made to include districts (the smallest geographical unit in the census) which consist of about 200 households (Carstairs and Morris 1991; Davey Smith et al. 2001; Jarman 1983; Townsend 1987). At first glance, the 'census section' (about 250 individuals) could denote a small area in Italy. However, the definitions of boundaries and total number of sections vary by census, causing a lack of comparability across years. Instead, this study focuses on 71 urban units (UUs) that reflect Genoa's historical origin, when many autonomous towns existed around the ancient city. UUs served as municipalities before Grande Genova was formed by law in 1926. The census sections were linked to UUs using a conversion table provided by the Genoa municipality. UUs have an average population of about 8000 individuals and presently, represent the smallest area with the ability to satisfy the need for population homogeneity and data availability. UUs have historically fixed boundaries and a population suitable to be identified as a small area, thus allowing for comparisons across years.

Third, deprivation indexes as a composite indicator can be developed using different standardisation methods for input variable values, alternative aggregation methods, and alternative weighting approaches (Saisana et al. 2005). However, the use of diverse methods could lead to varying results and uncertain conclusions.

While in the previous work (Ivaldi and Testi 2011) the GDI was obtained only by using an additive method, that is summing the $z$ scores of the input variables, the novelty of this paper is to test whether three different aggregation methods lead to different ranking of small areas (or 71 UUs of Genoa) or the ranking is stable with different methods. A Spearman correlation test was used to verify the stability of the methods' ranking. We introduce the three methods used below. 
(a) Additive aggregation method The additive index consists of the sum of the four unweighted $z$ scores. The first specification of the GDI deprivation index $\left(\mathrm{GDI}_{\mathrm{i}}^{\mathrm{Additive}}\right)$ is calculated as

$$
G D I_{i}^{\text {Additive }}=\frac{\sum_{j=1}^{4} z_{i, j}}{4}
$$

where

$$
z_{i, j}=\frac{\left(x_{i, j}-\mu_{j}\right)}{\sigma_{j}}
$$

where $z_{i, j}$ is the standardised value of each $j$ th indicator of each $i$ th $\mathrm{UU}, x_{i, j}$ is the original value of each $j$ th variable of each $i$ th $\mathrm{UU}, \mu_{j}$ is the mean of each $j$ th indicator, and $\sigma_{j}$ is the standard deviation of each $j$ th indicator.

The input variables were standardized because they are quantified in different units of measure. This avoids that some of them have more relevance with respect to the others (Jarman 1983; Townsend 1987; Townsend et al. 1988; Carstairs and Morris 1991; Forrest and Gordon 1993; Bartley and Blane 1994; Testi and Ivaldi 2009; Ivaldi and Testi 2011). Indeed standardization converts all indicators to a common scale. Therefore, for each observation we have calculated the $z$ scores for each of the variables under consideration, obtained by subtracting at each observation the value of the average of the UUs and dividing the result by the standard deviation of the UUs. The $z$ score of a variable, represents the number of standard deviations from its mean (Salzman 2003; Nardo et al. 2005).

(b) The second aggregation method follows the proposal of Mazziotta Pareto, that following the suggestion of Munda and Nardo (2005) which affirm that "if one wants the weights to be interpreted as "importance coefficients" (or equivalently symmetrical importance of variables) non-compensatory aggregation procedures must be used'.

The MPI is based on the assumption of 'non-substitutability' of dimensions, to which equal importance is attributed and no compensation is allowed between the dimensions. Therefore, The Mazziotta-Pareto approach (2007, 2012) is non-compensatory. In the past decade, the MPI has been adopted in Italy to discuss Millennium Development Goals (MDG) (De Muro et al. 2007), verify social inequality in regions (Mazziotta et al. 2010a), measure health infrastructure endowments (Mazziotta and Pareto 2011), assess the quality of life in provinces (Mazziotta and Pareto 2012), and measure political turnout to the polls (Ivaldi et al. 2017). We, therefore, aggregated the four indicators using the MPI method. Hereinafter, GDI calculated using the MPI

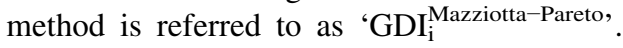

To construct the MPI, we first normalise individual indicators by 'standardisation' and then, aggregate the standardised indicators using an arithmetic algorithm with a penalty function based on 'horizontal variability', that is, the variability in standardised values for each unit. This variability, measured by the coefficient of variation, ensures that the UUs score with a higher imbalance between indicator values is penalised. Finally, the use of standardised deviation to calculate the synthetic index provides a measure which is robust and not highly sensitive to the removal of a single elementary indicator (Mazziotta et al. 2010b). The normalisation process is conducted as follows: 


$$
z_{i, j}=100+\frac{\left(x_{i, j}-\mu_{j}\right)}{\sigma_{j}} 10
$$

where $z_{i, j}$ is the standardised value of each $j$ th indicator of each $i$ th $\mathrm{UU}, x_{i, j}$ is the original value of each $j$ th variable for each ith $\mathrm{UU}, \mu_{j}$ is the mean of each $j$ th indicator, and $\sigma_{j}$ is the standard deviation of each $j$ th indicator.

For each UU, we calculated the average $z$ scores sum, relative standard deviation, and consequent coefficient of variation

$$
\mu_{z_{i}}=\frac{\sum_{j=1}^{4} z_{i, j}}{4}, \quad \sigma_{z_{i}}=\sqrt{\frac{\sum_{j=1}^{4}\left(z_{i, j}-\mu_{z_{i}}\right)}{4}}, \quad C V_{z_{i}}=\frac{\sigma_{z_{i}}}{\mu_{z_{i}}} .
$$

Then, the index is calculated as

$$
G D I_{i}^{\text {Mazziotta-Pareto }}=\mu_{z_{i}}-\sigma_{z_{i}} c v_{z_{i}}
$$

where $G D I_{i}^{\text {Mazziotta-Pareto }}$ is the index value for each $i$ th UU.

This approach is characterised by the use of the function $\left(\sigma_{z_{i}} c v_{z_{i}}\right.$ to penalise units with imbalanced values for the partial composite indices. The penalty is based on the coefficient of variation and is zero if all values are equal. The objective is to favour areas whose means are equal and that demonstrate greater balance among the different deprivation dimensions (Mazziotta and Pareto 2012). We, therefore, aggregated the indicators of each dimension and summed the partial composite indices as per the MPI method.

(c) Pena method (also known as the P2 distance or DP2 method): The method was proposed by Peña (1977). The application of DP2 has been increasing (Nayak and Mishra 2012), particularly since Somarriba and Pena (2009) conducted their study using DP2 and criticised both principal component analyses and data envelopment analyses. On the other hand some refinement to the method have been suggested (Montero et al. 2010). The DP2 method is an iterative procedure that weighs partial indicators depending on their correlation with the global index. This construction solves a large number of problems, for instance, aggregating variables expressed in different units of measurement, arbitrary weights, missing values, and duplicate information (Montero et al. 2010; Peña 1977; Somarriba and Pena 2009). Nevertheless, it has several desirable properties: non-negativity, commutativity, triangular inequality, existence, determination, monotony, uniqueness, transitivity, invariance to change of origin and/or scale of units in which the variables are defined, invariance to changes in general conditions, exhaustiveness, and reference base (Nayak and Mishra 2012). We, therefore, aggregated the four indicators using the DP2 method. Hereinafter, the GDI calculated using the Pena method is known as $G D I_{i}^{\text {Pena }}$.

Pena's P2 distance is as follows:

$$
G D I_{i}^{\text {Pena }}=\sum_{j=1}^{4}\left[\left(\frac{d_{i j}}{\sigma_{j}}\right)\left(1-R_{j, j-1, \ldots 1}^{2}\right)\right],
$$

where $i=1,2, \ldots, \mathrm{n}$ are cases, that is, the $71 \mathrm{UUs} ; J$ are the constituent indicators (house ownership, unemployment rate, low education level, and household overcrowding), where $j=1,2, \ldots, 4 ; d_{i, j}$ is defined as $d_{i, j}=\left|x_{i, j}-x_{\rho, j}\right|$, where $x_{i, j}$ is the value assumed by any 
indicator $j$ for any $\mathrm{UU} i ; \rho$ is the reference case pertaining to $\min _{i}=\left(x_{i, j}\right)$; and $\sigma_{j}$ is the standard deviation of variable $j$.

As Montero et al. (2010) and Mishra (2012) pointed out, quantity $\frac{d_{i, j}}{\sigma_{j}}$ is merely a change in origin and scale and one may also use zero as the reference $\rho$ point and $\left[\max _{i}\left(x_{i j}\right)-\min _{i}\left(x_{i j}\right)\right]$, instead of $\sigma_{j}$, as a scaling factor without adversely affecting the formula. The key factor, however, is in the weights $\left(1-R_{j, j-1, \ldots 1}^{2}\right) . R_{j, j-1, \ldots 1}^{2}$, that are the coefficient of determination of the regressions run on the $j$ chosen. The number of regression run is equal to the number of indicators or input variables used minus one (the $j$ chosen, which are included in the regression one by one. It should be noted that the first variable obtains an absolute weight of unity $\left(1-R_{1}^{2}\right)$ because it is regressed on itself. The subsequent variable $j=2$ has weight $\left(1-R_{2,1}^{2}\right)$, the third $j=3$ is $\left(1-R_{3,2,1}^{2}\right)$, and in general, the $j$ th variable assumes $\left(1-R_{j, j-1, \ldots 1}^{2}\right)$. In synthesis, the chosen $j$ is regressed on other indicators included one by one. In this study, we conduct three regressions, where the first has one has regressor and the third has three. The resulting $R_{j, j-1, \ldots 1}^{2}$ for any $j$ is used as a sort of weight. In this way, the weight assigned to each indicator follows a precise rule that aims to reduce the duplicity of information that often affects aggregation methods (Montero et al. 2010; Somarriba and Pena 2009).

Note that the weights assigned to a variable depend on its position in the order, making DP2-based composite synthetic indices indeterminate and arbitrary. To resolve the aforesaid indeterminacy, Montero et al. (2010) suggested the following iterative procedure:

1. Initialise the weight vector, $w_{j}=1 \forall j=1,2,3,4$, and define $\varepsilon=0.00001$ for accuracy.

2. Define $\partial_{i, j}=\frac{d_{i, j}}{\sigma_{j}} \forall j=1,2,3,4$ and $i=1,2, \ldots, n$.

3. Obtain $D F_{i}=\sum_{j=1}^{4}\left[\left(\frac{d_{i, j}}{\sigma_{j}}\right) w_{j}\right] ; i=1,2, \ldots, n$.

4. Compute the Karl Pearson correlation coefficient, $r\left(D F, \partial_{j}\right)$, between DF and $\partial_{j}$ $\forall j=1,2,3,4$.

5. Arrange $\left|r\left(D F, \partial_{j}\right)\right|$ in the descending order and accordingly, re-index the associated variables, $\partial_{j}$.

6. Compute $Z_{i}=\sum_{j=1}^{4}\left[\left(\frac{d_{i, j}}{\sigma_{j}}\right) w_{j}\right] ; i=1,2, \ldots, n ; w_{j}\left(1-R_{j, j-1, \ldots 1}^{2}\right) \forall j=1,2,3,4 ;$ and $w_{j}=1$

7. If $\sum_{i=1}^{n}\left(D F_{i}-Z_{i}\right) \geq \varepsilon$, replace $\mathrm{DF}$ with $\mathrm{Z}$ and return to Step 4; otherwise, stop.

In conclusion, the four input variables have been aggregated using three methods to test the stability of the results.

\subsection{Health Status}

Health status can be evaluated as the prevalence of a particular disease, the mortality, the self-assessed health status or quality of life. In this work Health status was evaluated using premature mortality for all causes of death. The cut-off point to define a premature death was set at 65 years old (Carstairs and Morris 1991; Benach and Yasui 1999; Exeter et al. 2011). Standardised mortality ratios (SMRs) computed for each UU by standardising sex and age as the ratio between observed premature deaths (0-65 years) and expected ones, that are, the hypothetical occurrence of a death in each area if the genoa death rates was applied to each areas. The death records analysed refer to the 3 years following the census year (e.g. for the 1991 census, the mortality rate is for 1992-1994) and are collected from the Genoa Municipality Registry. 


\subsection{Relationship Between Deprivation and Health}

Deprivation and health are compared by conducting correlation analyses and creating classes with a homogenous deprivation level. Each UU is ranked according to the scores of the deprivation indexes.

The UU ranking offers a first-hand picture of the relative deprivation between areas. The Pearson correlation index between GDI and SMR is used to determine the association between socioeconomic conditions, as proxied by GDI, and health status. Then, by performing classification cluster analyses using algorithm k-means (Hartigan and Wong 1979), the UUs are classified into six deprivation classes and SMRs are calculated for each of them. The objective of conducting cluster analyses is to classify UUs on the basis of their deprivation, thus creating homogenous deprivation classes with respect to GDI scores. In addition, cluster analyses allow us to assign greater importance to the deprivation score, rather than relative ranking position, as a criterion to split classes. In contrast with the use of quintiles this approach allow the unit to distribute according only to the score, and they are not forced to be classified in a specific class. In sum, this approach can highlight the presence of extreme situations and help create more homogeneous deprivation classes that indicate the distribution of 'real' small areas distribution on the basis of their deprivation level.

\subsection{Changes Over Time}

Deprivation indexes are a relative measure of deprivation. They are context- and timespecific scores. In addition, the scores calculated for one town are not directly comparable with another town,. An index developed for urban areas will not be effective in identifying the level of deprivation in rural areas (Barnett et al. 2001; Bertin et al. 2014; Gilthorpe and Wilson 2003). Moreover, deprivation scores calculated for one census year are not directly comparable with those estimated for another census year. This can be attributed to the following reasons. First, social conditions and the relative importance of a particular indicator may vary, and thus, it is necessary to include in the index only those variables that can sufficiently capture deprivation during the study period. Second, geographical areas taken as reference can vary over time because of administrative reasons or choice of national statistical institutions. If the boundary of the areas taken as reference change, it is difficult to precisely compare such changes in small areas (Exeter et al. 2005, 2011) or it is necessary to use techniques developed to convert data between geographies (Gregory 2002; Norman 2010; Schroeder 2007). Finally, the score recorded at one census is relative to the situation in that year. Thus, a ward may have the same score during successive censuses but become more or less deprived over time in comparison with other wards. Small areas are classified in ranking and then divided into different deprivation classes using quintiles; however, the rankings are not comparable across years because area $X_{i}$ 's better position can be attributed to both an actual improvement in the area or the worsening of another area. On the other hand, a ward may report consistent scores for successive censuses, but this does not indicate the same deprivation level because the index calculation has different reference points.

In this study, we address these problems to evaluate the evolution of the relationship between socioeconomic deprivation and health outcomes for 1991-2011. First, all four indicators used to build the GDI index are included in the three censuses (1991, 2001, and 2011). Since the indicators have been validated in previous works during 1991 and 2001 
and adopted in the most recent deprivation studies (Allik et al. 2016; Panczak et al. 2012), they serve as good proxies for deprivation for the study period. As for geographic area, it is important to choose a small area which is homogenous and has consistent stable boundaries over time.

The census section of about 250 individuals used in the Italian censuses can be treated as a small area, but the definitions of its boundaries and the total number of sections change almost every year, making it difficult to conduct a comparative study. There are other census areas with boundaries subject to fewer changes over the years; however, they cover a wide area and population, and, therefore cannot be considered as small area. On the other hand, UUs have historically fixed boundaries and a population rate suitable to be identified as a small area and can be used for time comparison.

Deprivation indexes are relative to a specific time point because of the manner in which they are built. For example, using the additive method, the mean and standard deviation used to normalise data refer to a specific year. In this study, we address the problems associated with using period-specific deprivation scores by combining census data from 1991, 2001, and 2011 for each of the 71 UUs. We 'stack' the 71 UUs for each census year and accordingly, calculate the index (Exeter et al. 2011; Norman 2010).

Formalising this approach, Eqs. (1) and (2) can be calculated using

$$
\begin{gathered}
\mu_{j}=\frac{\sum_{i=1}^{n} x_{i, j, t_{1}}+\sum_{i=1}^{n} x_{i, j, t_{2}}+\sum_{i=1}^{n} x_{i, j, t_{3}}}{3 n}, \\
\sigma_{j}=\sqrt{\frac{\sum_{i=1}^{n}\left(x_{i, j, t 1}-\mu_{j)+} \sum_{i=1}^{n}\left(x_{i, j, t 2}-\mu_{j)+} \sum_{i=1}^{n}\left(x_{i, j, t 3}-\mu_{j}\right)\right.\right.}{3 n}},
\end{gathered}
$$

where $i=1,2, \ldots, \mathrm{n}$ denote the $71 \mathrm{UUs} ; j=1,2,3,4$ are the deprivation indicators; and $t=1991$, 2001, 2011 are the three census years.

Equation (3) uses the standard deviation $\sigma_{j}$ (Eq. 4) and distance $d_{i, j}=\left|x_{i, j}-x_{\rho, j}\right|$, where $\rho$ is the reference case pertaining to $\min _{i}=\left(\left(x_{i, j}\right)_{t}\right)$.

In general,

$$
\begin{gathered}
\mu_{j}=\frac{\sum_{t=1}^{k} \sum_{i=1}^{n} x_{i, j, t}}{k n} \\
\sigma_{j}=\sqrt{\frac{\sum_{t=1}^{k} \sum_{i=1}^{n}\left(x_{i, j, t}-\mu_{j}\right)}{k n}} \\
\min _{i}=\left(\left(x_{i, j}\right)_{t}\right)
\end{gathered}
$$

where $i=1,2, \ldots, \mathrm{n}$ denote the number of small areas; $j=1, \ldots, \mathrm{m}$ are the variables used in the indicator; and $t=1, \ldots, \mathrm{k}$ are the number of censuses used.

\section{Results}

\subsection{Deprivation: Genoa Deprivation Index}

First, we computed the results for the three methods-additive, MPI and DP2 (see Appendix 2). We then arranged the scores and accordingly, determined the rankings and 
successively the number of class for each UU are reported in the last columns (see Appendix). To verify the stability of the index, we used Spearman's rank correlation coefficient to compare the distribution of ranks for the proposed indexes. We found that the stability of the results obtained using the different methods is satisfactory. When conducting a comparison for the years analysed in this study, Spearman's coefficient approach unity (0.96-0.99) (Table 2). The choice of aggregation method does not significantly affect the areas' rank. This result is of importance because it shows that the ranking obtained for the index on the basis of the chosen variables is somewhat meaningful. Moreover, a similar output was obtained using both a compensatory methodology (DP2) and non-compensatory construction (MPI). Thus, we can conclude that the selected variables offer a good foundation to describe the phenomena under scrutiny since the ranking is not negatively influenced by the compensation among dimensions.

We first compare data for 1991-2011 on the basis of the rankings, which should elucidate the relative changes in UUs' deprivation levels. According to Spearman coefficients, the rankings do not drastically change, although internal mobility appears to exist in the case city (Table 3). In particular, the period from 2001 to 2011 depicts a greater ranking change. This means that major changes (lower Spearman rho) are mainly influenced by sociological and economic phenomena, such as population aging, de-industrialisation, and urban requalification, which may have occurred in the recent past. Thus, this tool can be used to gain a deeper understanding of which areas in the city have improved or worsened on the basis of their deprivation levels compared to other UUs (see Appendix 3).

Although these results are useful, they refer to a relative concept. The comparison is limited to, for example, 'the UU has improved with respect others', and thus, we cannot determine whether an area has actually improved in its deprivation status. Nevertheless, the scores obtained using the stacking method gives us a broad understanding of how deprivation has globally evolved over time. Next, we present the results for $G D I_{i}^{\text {Pena }}$ because the other two indicators offer similar results.

Figure 1 shows that Genoa's deprivation level decreased during the study period. We conducted a Friedman test (1937), which is generally used for a one-way repeated measures analysis of variance by ranks, to confirm the statistical significance of the decline in the UUs' deprivation scores (Appendix 4). The variability or dispersion and the max-min difference for each year suggest the narrowing of deprivation disparities among UUs (Table 4).

Figure 2 is a Kiviat graph of the four variables and shows that the improvement paths are not equal for each indicator. All, except house ownership, report improvements. The highest rate of households living in rented homes was recorded in 2011.

Table 2 Comparison of rankings between methods (Spearman coefficients)

\begin{tabular}{|c|c|c|c|c|c|c|c|c|c|}
\hline & \multicolumn{3}{|l|}{1991} & \multicolumn{3}{|l|}{2001} & \multicolumn{3}{|l|}{2011} \\
\hline & Additive & MPI & $\mathrm{D} 2 \mathrm{P}$ & Additive & MPI & $\mathrm{D} 2 \mathrm{P}$ & Additive & MPI & $\mathrm{D} 2 \mathrm{P}$ \\
\hline Additive & 1 & 0.995 & 0.993 & 1 & 0.997 & 0.986 & 1 & 0.988 & 0.988 \\
\hline MPI & & 1 & 0.984 & & 1 & 0.989 & & 1 & 0.969 \\
\hline D2P & & & 1 & & & 1 & & & 1 \\
\hline
\end{tabular}


Measuring Change Over Time in Socio-economic Deprivation...

Table 3 UUs mobility rankings mobility over years (Spearman coefficients)

\begin{tabular}{llll}
\hline & $\begin{array}{l}\text { First period } \\
1991-2001\end{array}$ & $\begin{array}{l}\text { Second period } \\
2001-2011\end{array}$ & $\begin{array}{l}\text { Overall period } \\
1991-2011\end{array}$ \\
\hline$G D I_{i}^{\text {Additive }}$ & 0.96 & 0.92 & 0.91 \\
$G D I_{i}^{\text {Mazziotta-Pareto }}$ & 0.97 & 0.91 & 0.89 \\
$G D I_{i}^{\text {Pena }}$ & 0.95 & 0.91 & 0.92 \\
\hline
\end{tabular}

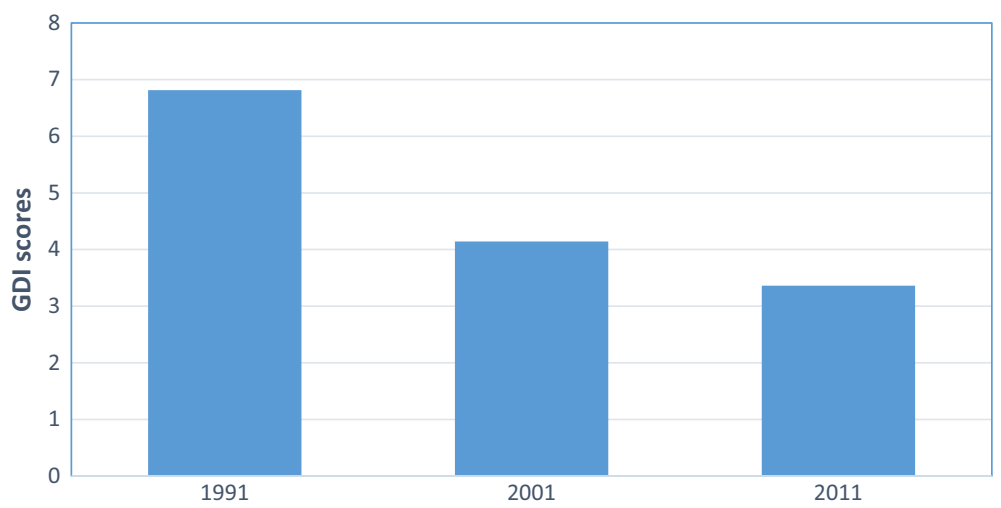

Fig. 1 Average $G D I_{i}^{P e n a}$ scores per year

Table 4 Global $G D I_{i}^{\text {Pena }}$ descriptive statistics

\begin{tabular}{lllllll}
\hline Year & No. & Mean & Standard deviation & Min & Max & Diff max-min \\
\hline 1991 & 71 & 6.8147 & 2.17262 & 3.27 & 16.02 & 12.74 \\
2001 & 71 & 4.1417 & 1.68398 & 1.37 & 11.53 & 10.16 \\
2011 & 71 & 3.3619 & 1.30200 & 1.12 & 8.74 & 7.62 \\
\hline
\end{tabular}

Fig. $2 G D I_{i}^{P e n a}$ indicators for 1991-2011

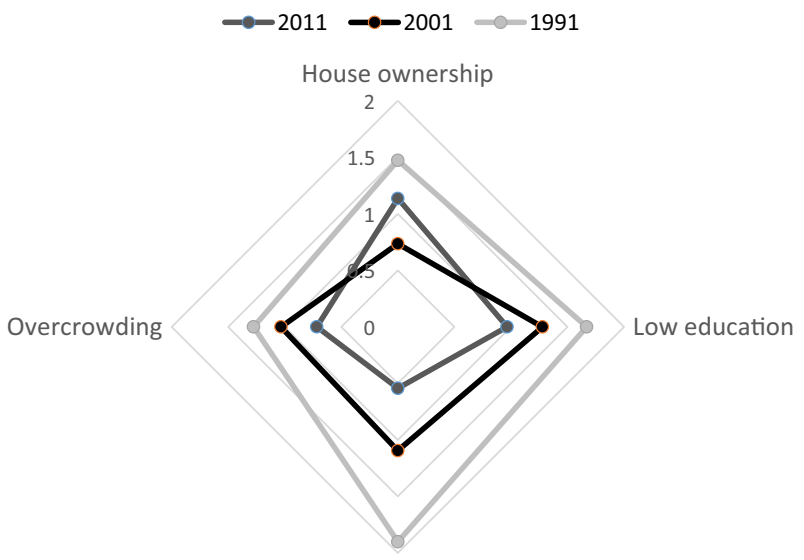

Unemployment 
Overall, the deprivation level in Genoa reduced across all census years; however, it is noteworthy that not all UUs reported the same degree of improvement. While some UUs showed higher than average improvement, others demonstrated lower levels. For 2001 and 2011, the deprivation level increased for seven UUs (Appendix 5).

Using algorithm k-means, every UU is assigned to a deprivation class for each census year. The UUs are classified on the basis of their GDI scores, rendering it possible to not have a uniform distribution across classes. Thus, we conducted cluster analyses because they are more flexible than the often-used quintiles approach and highlight the presence of extreme situations. Figures 3, 4 and 5 show us that the UUs are almost equally distributed across classes in 1991 and 2001. In 2011, however, the UUs are more condensate in the second and third deprivation classes. This can be attributed to the lower level of deprivation and dispersion of GDIs score. The class clustering reveals that UU no. 3 (Cà Nuova) has the highest deprivation level and is the only UU to be classified under the sixth class. This underline a really high deprived area.

\subsection{Health Status}

Table 5 presents data on Genoa's health status, particularly the number of premature deaths for the three periods. Globally, it appears that the number of premature deaths decreased across the study period.

Table 6 presents the results for the correlation analysis conducted to verify the association between deprivation and health outcomes. Pearson's $\rho$ shows that a relationship exists and endures over the years. It is particularly high in 2001, while is lower but significant in 1991 and 2011.

Table 7 depicts the all-cause premature mortality SMRs for the three time periods on the basis of the six deprivation classes. In particular, it shows that SMRs were the lowest in areas classified as the least deprived during 1992-1994 (CI 95\%; 0.78), 2002-2004 (CI 95\%; 0.82), and 2012-2014 (CI 95\%; 0.75).

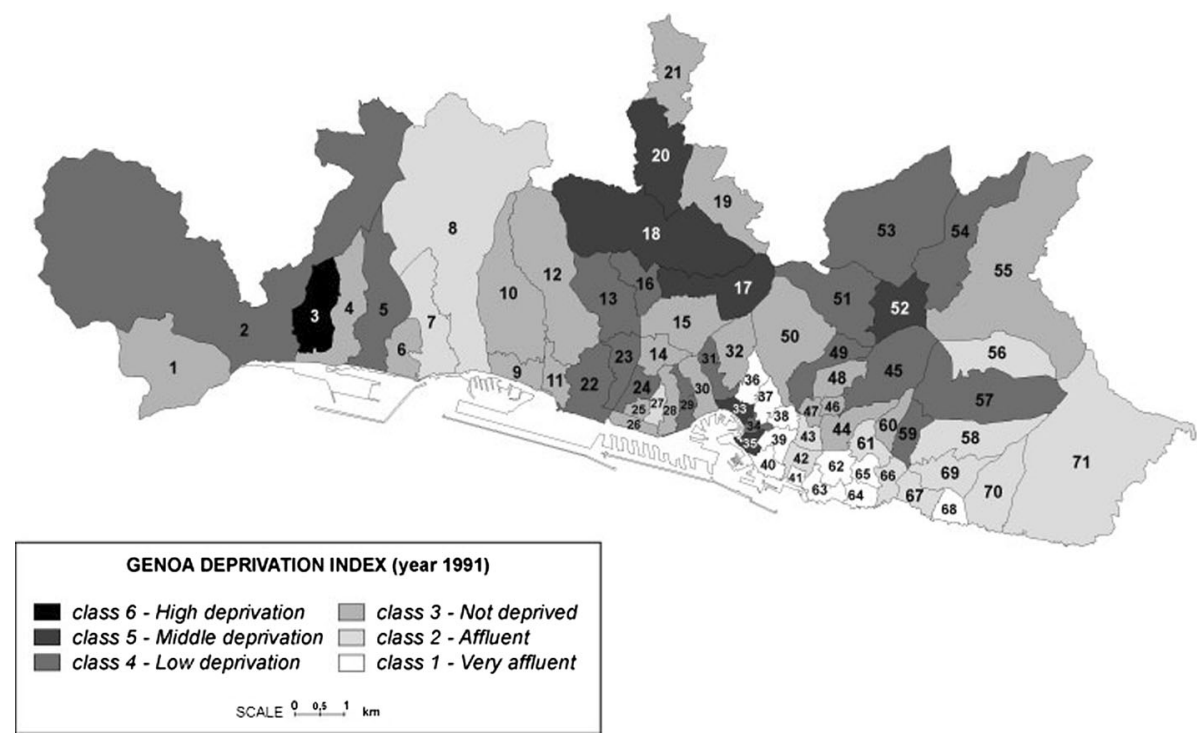

Fig. 3 UUs categorised by deprivation class, 1991 


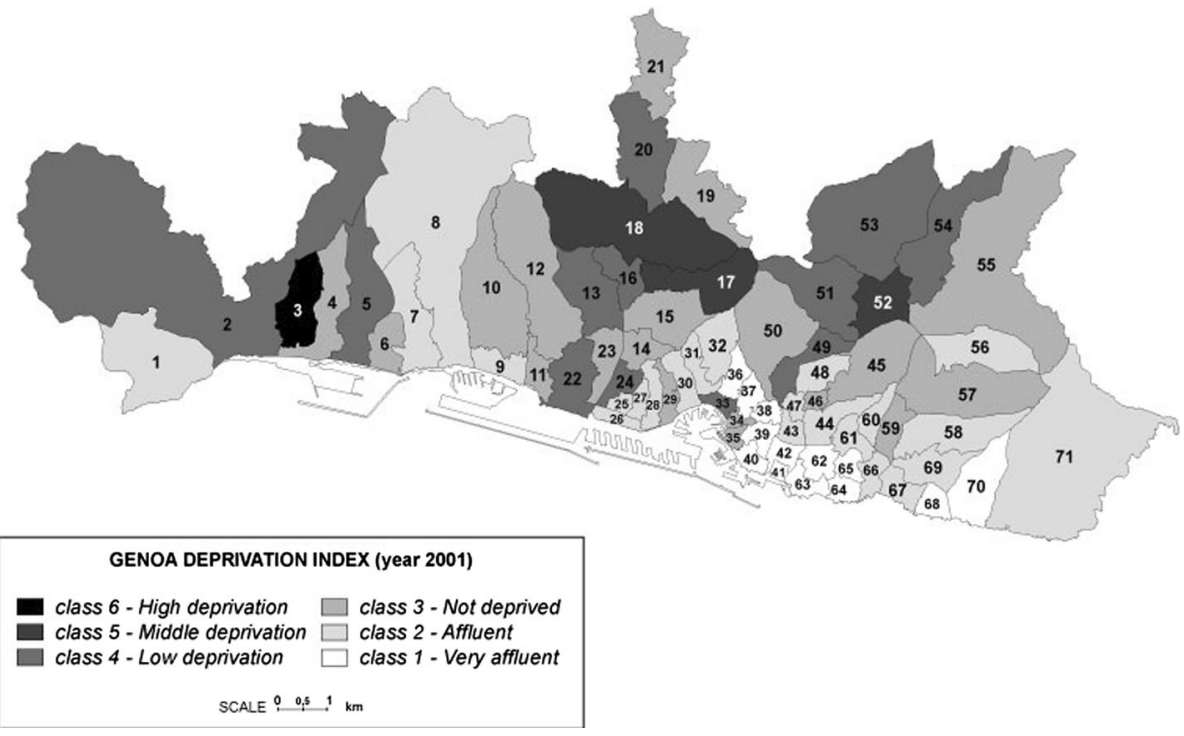

Fig. 4 UUs classified by deprivation class, 2001

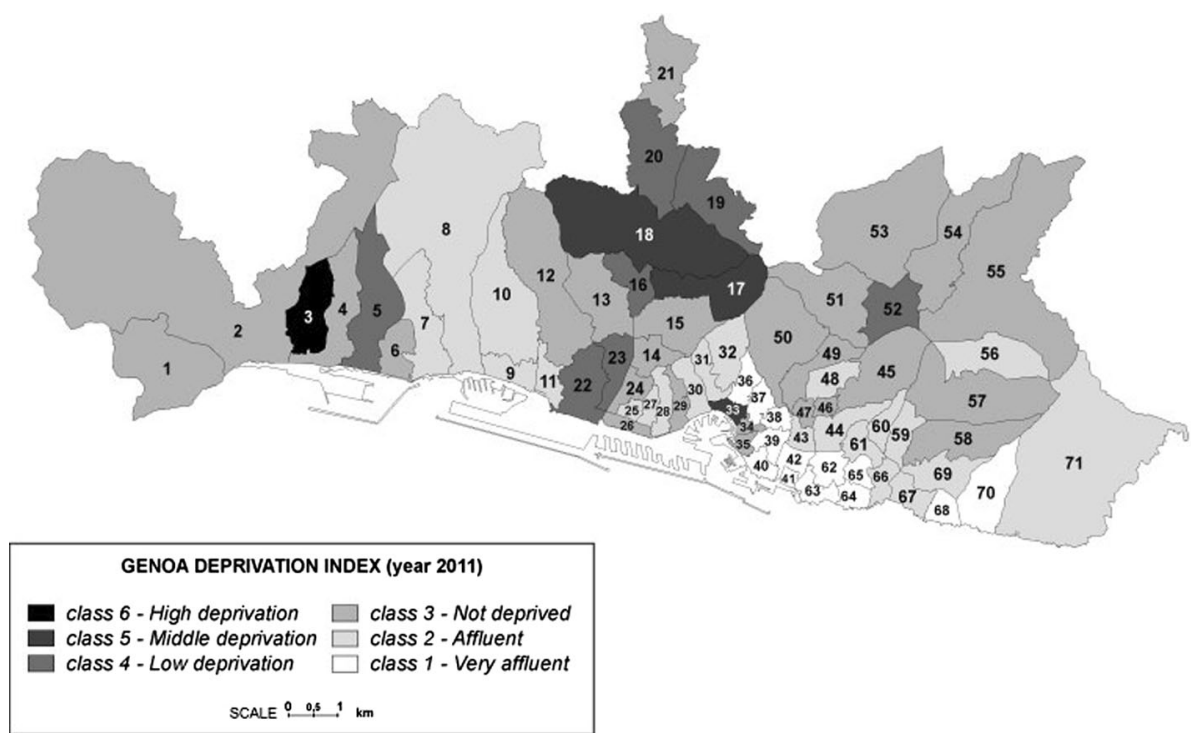

Fig. 5 UUs divided by deprivation class, 2011

\section{Discussion}

Studies have shown that area-level deprivation not only serves as an individual-level proxy when data are unavailable but also has its own impact (Hagedoorn et al. 2016; Spadea et al. 2010). Moreover, policy decisions regarding, for example, resources allocation and healthcare organisations, are made on a larger scale than individual or census section 
Table 5 Number of premature deaths in Genoa

\begin{tabular}{lcrr}
\hline & \multicolumn{2}{l}{ Years } & \\
\cline { 2 - 4 } & $1992-1994$ & $2002-2004$ & $2012-2014$ \\
\hline Death of those under 65 years & 4495 & 3003 & 2381 \\
Population aged under 65 years & 534,938 & 454,124 & 426,666 \\
Ratio/100,000 inhabitants & 840.2 & 661.2 & 558.0 \\
\hline
\end{tabular}

Table 6 Relationship between GDIs and SMRs (Pearson's $\rho$ )

\begin{tabular}{llll}
\hline GDIs & SMR 1991 & SMR 2001 & SMR 2011 \\
\hline$G D I_{i}^{\text {Additive }}$ & 0.37 & 0.58 & 0.47 \\
$G D I_{i}^{\text {Mazziotta-Pareto }}$ & 0.34 & 0.58 & 0.47 \\
$G D I_{i}^{\text {Pena }}$ & 0.4 & 0.62 & 0.48 \\
\hline
\end{tabular}

Table 7 Deprivation classes and standard mortality ratio across years

\begin{tabular}{lllll}
\hline Class number & Definition & $\begin{array}{l}\text { SMR }<65-1991 \\
(\mathrm{CI} 95 \%)\end{array}$ & $\begin{array}{l}\text { SMR }<65-2001 \\
(\mathrm{CI} 95 \%)\end{array}$ & $\begin{array}{l}\text { SMR }<65-2011 \\
(\mathrm{CI} 95 \%)\end{array}$ \\
\hline 1 & Most affluent & 0.78 & 0.82 & 0.75 \\
& & $(0.71-0.85)$ & 0.92 & $(0.67-0.84)$ \\
2 & 0.93 & $(0.86-0.98)$ & 0.95 \\
& & $(0.86-0.99)$ & 1.06 & $(0.88-1.01)$ \\
3 & 0.96 & $(0.99-1.14)$ & 1.08 \\
& & $(0.91-1.01)$ & 1.11 & $(0.98-1.12)$ \\
4 & 1.11 & $(1.03-1.20)$ & 1.18 \\
& & $(1.05-1.17)$ & 1.32 & $(1.06-1.32)$ \\
5 & 1.36 & $(1.12-1.55)$ & 1.27 \\
& & $(1.23-1.49)$ & 2.01 & $(1.15-1.65)$ \\
6 & 1.06 & $(1.62-2.5)$ & 1.73 \\
& & $(0.81-1.56)$ & & $(1.31-2.40)$ \\
\hline
\end{tabular}

levels. Therefore, a system that can compare deprivation indexes over time using census data can be a useful and inexpensive instrument that supports decision makers.

A key contribution of this study to the extant literature is its formalisation of a methodological path to compare deprivation and health outcomes across years. This structured approach can be applied to several contexts. Moreover, different from other indexes, the GDI comprises indicators that can describe both current deprivation level and that during the lifespan considered (in this case, 1991-2011). The use of several aggregation methods, both compensatory and non-compensatory, allows us to test the ability of 
the indicators to monitor deprivation. Further, consistent geographic zones enable us to calculate a deprivation index by combining censuses data for 1991, 2001, and 2011 and explore changes in the mortality or deprivation gradient by conducting standard geographical comparisons.

We derived the following findings from the present case study of the city of Genoa. First, we were able to determine how deprivation levels in certain areas have changed relative to others on the basis of rankings. More specifically, we identified areas which have widely improved or worsened in their position and examined the mobility of areas to establish the reasons underpinning such changes. In Genoa, for example, UUs Maddalena and Porto improved in ranking possibly because of the strong re-qualification of the area near the old port. In addition, Oregina showed improvement probably owing to the designation of buildings to host a university department. Second, we showed how city-wide deprivation has changed during the study period for the entire city and each area. This gave us further insight into how each deprivation indicator changed over time and their tendential contribution to decreasing deprivation. Since 1991, the overall deprivation in Genoa has decreased and each indicator has improved, except for house ownership, which worsened in 2011 compared to 2001. This clearly suggests that the improvement path differs by UU. To this effect, it would be useful to highlight UUs that have shown significant improvement and to understand the factors leading the improvement.

Third, the clustering of UUs into deprivation classes helped create homogeneous areas of deprivation comparable with their respective health outcomes, in this case, premature mortality or SMRs. Moreover, using a flexible method, it is possible to explore how areas move from one class to another and underscore the potential presence of area with extreme deprivation. In Genoa, we found one UU where deprivation was the highest and persistent over years and a defined area comprising UUs with persistently least deprivation levels. Further, we were able to observe class changes for other areas, which were generally improving trends. There is evidence that fewer UUs were grouped in the last three deprivation classes in 2011 compared to 1991. On the other hand, a higher number of UUs were classified under the second and third deprivation class. This denotes the general improvement and in particular, lowering dispersion in deprivation scores. Finally, we were able to explore how the relationship between deprivation and health outcomes changes over time. In Genoa, people who live in deprived areas had higher SMRs, which is in line with the findings in the literature. However, in 2011, fewer UUs were classified as deprived areas, with a lower rate of population at a higher risk compared to the previous census years (Appendix 6).

This study is not free from limitations. First, UUs do not have the same number of inhabitants: few UUs reported a population of about 1000-2000 individuals, whereas few others recorded about 10,000. Second, the GDI is built to cover deprivation in an urban area and thus, is sensitive to urban-rural differences (Barnett et al. 2001; Bertin et al. 2014; Gilthorpe and Wilson 2003). While the proposed approach can be replicated in an urban context, the indicators used may be not able to describe deprivation in rural areas. For example, housing tenure has been indicated as a biased measure of deprivation in the rural context (O'Reilly et al. 2007). However, some studies have shown that it is possible to test the ability of a small area deprivation index to describe deprivation even in rural areas (Bertin et al. 2014), which we leave for future works. 


\section{Conclusions}

While deprivation inequalities continue to exist in Genoa, at a global level, these inequalities are gradually reducing. More specifically, the rate of premature mortality has shown an improvement over the years. In addition, the number of areas classified as and population living in deprived areas is declining. However, despite this, our case study confirms the existing finding that socioeconomic conditions significantly affect health status. In fact, GDI is associated with SMRs for premature deaths, with a positive Pearson $\rho$ value for every year and people living in deprived area reporting consistently higher SMRs. Thus, we recommend that future works analyse the relationship between material deprivation and specific causes of death over time to enhance the understanding of how deprivation can affect health outcomes. It would also be interesting to couple GDI with a social deprivation index to conduct a long-term comparison of changes in the two dimensions. Further, researchers could examine changes in deprivation and health inequalities to identify factors contributing to improvements in an area (i.e. urban requalification, access to healthcare, and new bus lines or shops). To do so, a wider sample of cities or areas should be compared to establish benchmarks for interventions aimed at lowering deprivation levels. This would make it possible to explicitly account for the impact of public choices on cost-benefit analysis models.

This study serves as a first step to understanding why certain city areas report higher improvement levels than others. This will be useful in understanding the key factors influencing improvements in an area's status. The use of a structured method to assess deprivation and health outcomes over time can help decision makers evaluate policy impact (health and social policies) and efficiently allocate resources. Finally, we hope that the evidence provided in this study encourages researchers to conduct an in-depth investigation of factors determining area deprivation and health changes in the long run.

\section{Appendix 1}

See Table 8 . 


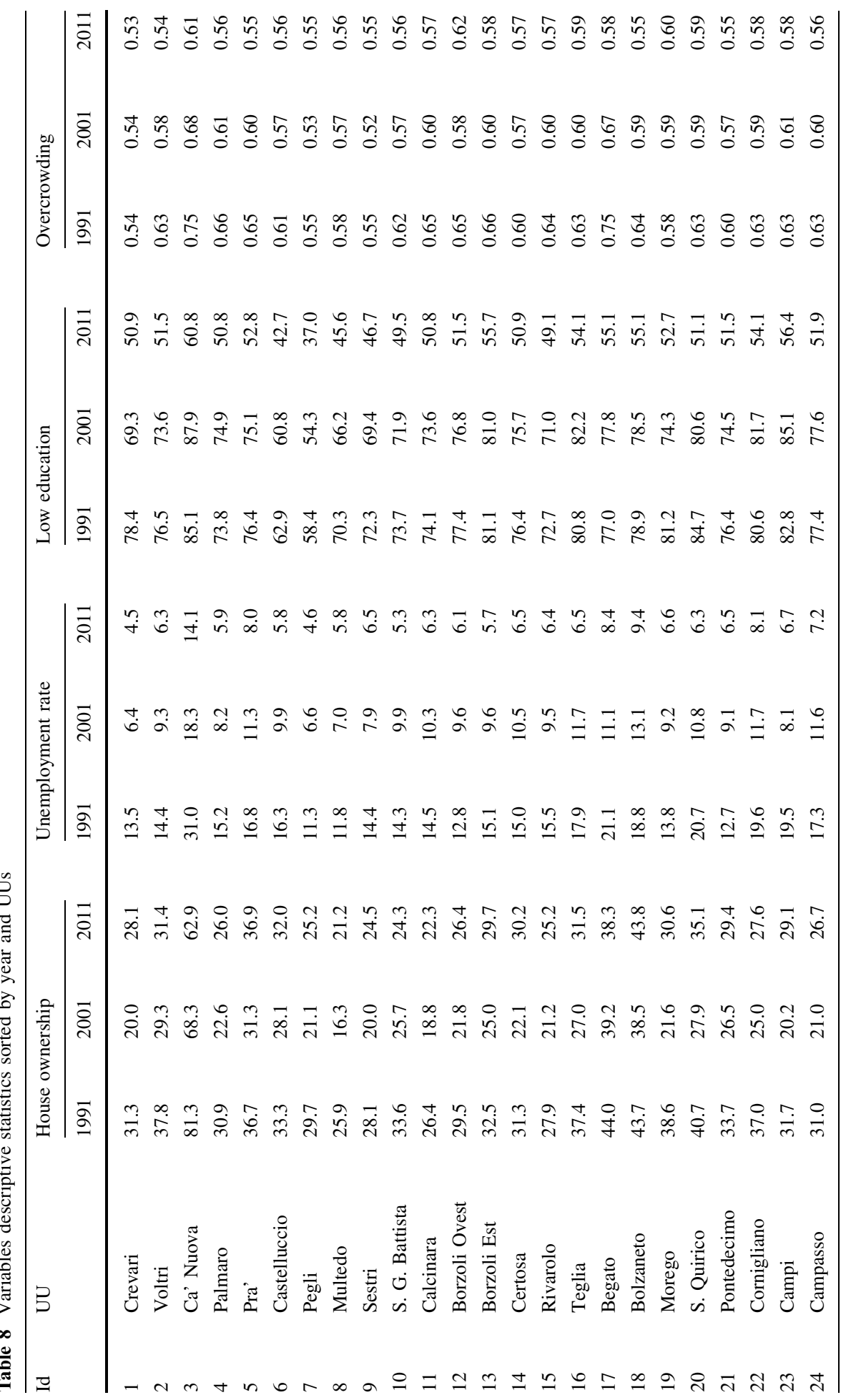


S. Landi et al.

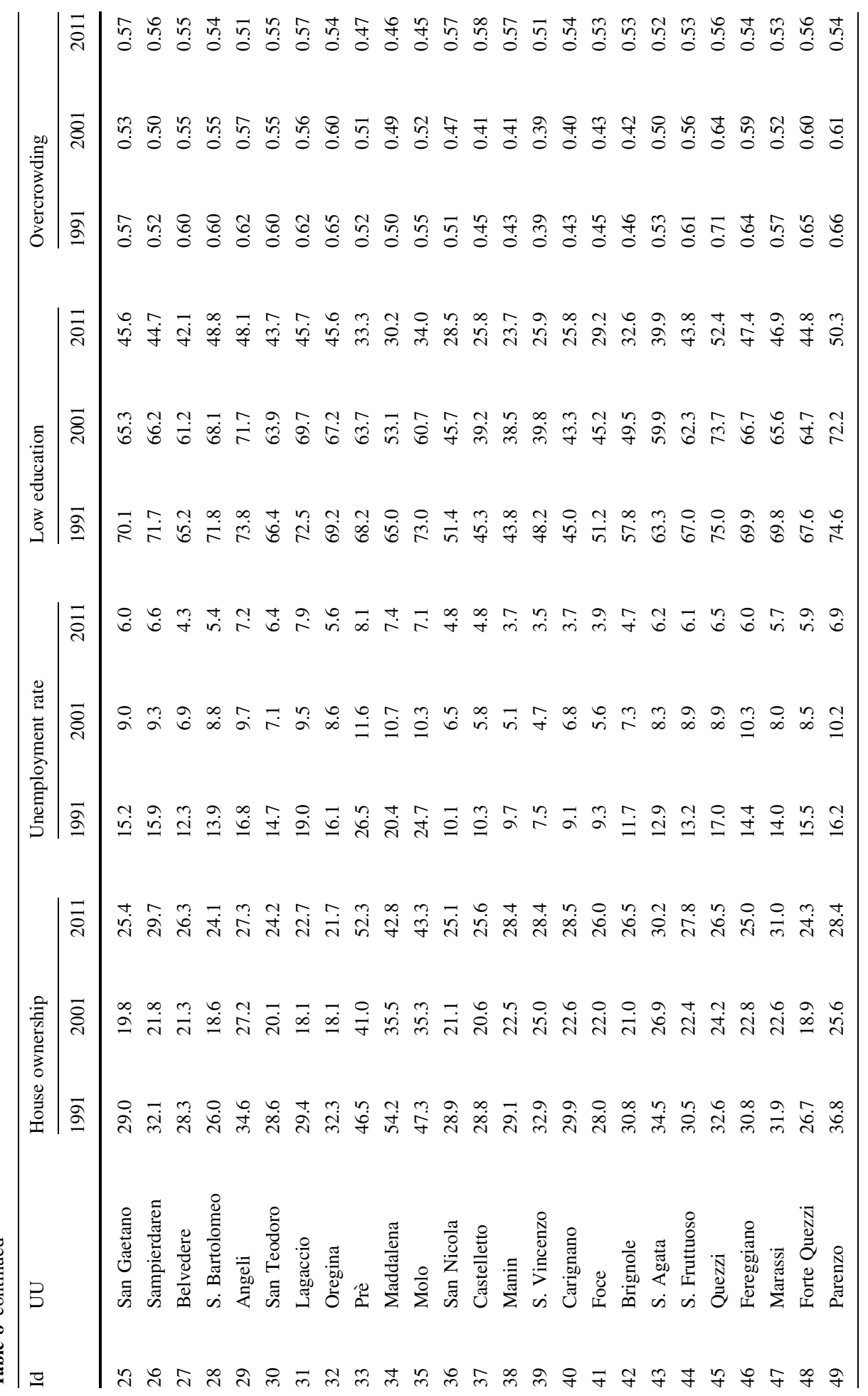




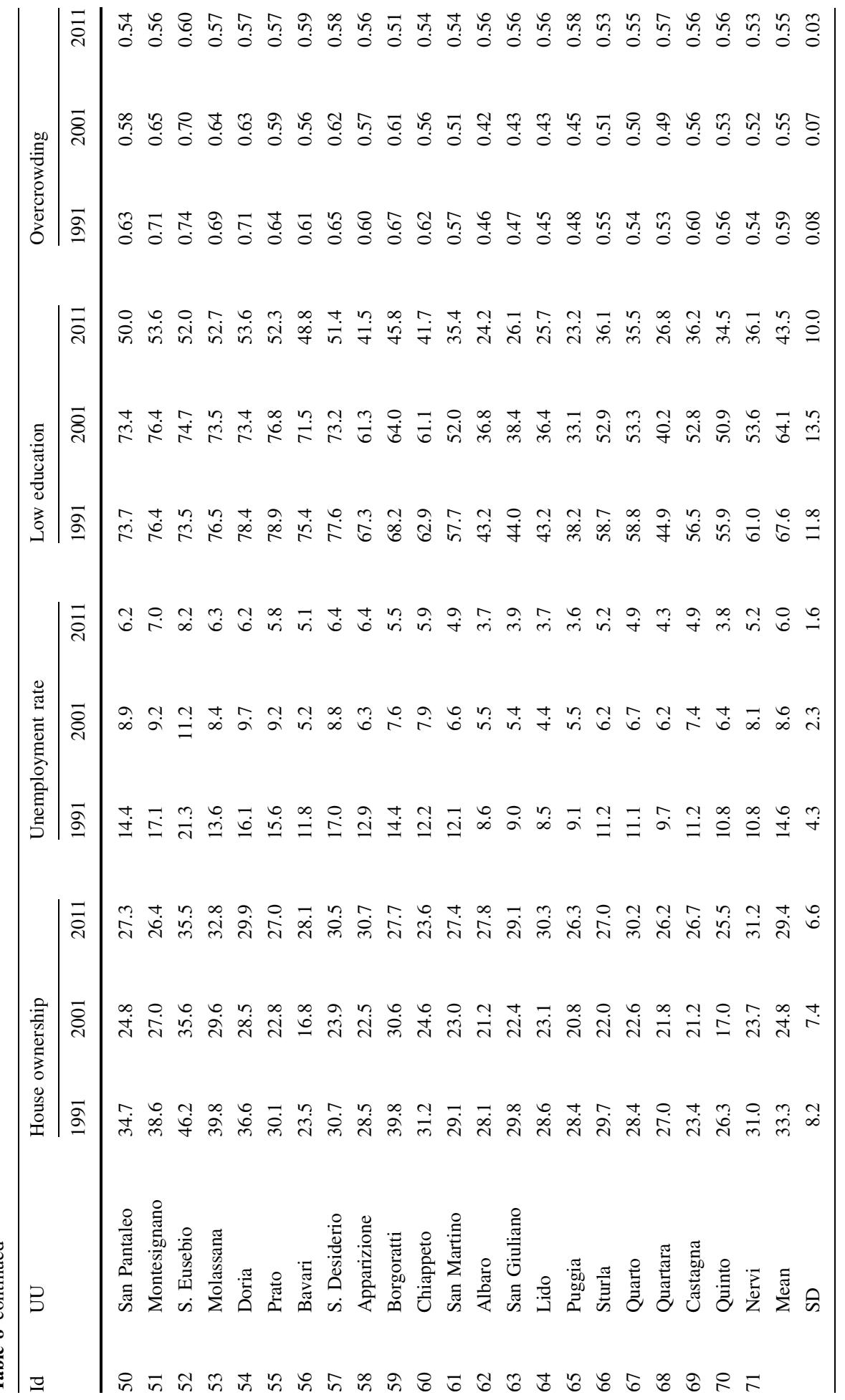




\section{Appendix 2}

See Tables 9, 10, 11, 12, 13, 14, 15, 16 and 17.

Table 9 GDIs 2011-DP2 method

\begin{tabular}{|c|c|c|c|c|}
\hline ID & Uus & GDIs score & Ranking & Deprivation class \\
\hline 65 & Puggia & 1.12 & 1 & 1 \\
\hline 39 & S. Vincenzo & 1.17 & 2 & 1 \\
\hline 41 & Foce & 1.29 & 3 & 1 \\
\hline 40 & Carignano & 1.30 & 4 & 1 \\
\hline 38 & Manin & 1.30 & 5 & 1 \\
\hline 37 & Castelletto & 1.37 & 6 & 1 \\
\hline 62 & Albaro & 1.53 & 7 & 1 \\
\hline 63 & San Giuliano & 1.57 & 8 & 1 \\
\hline 64 & Lido & 1.61 & 9 & 1 \\
\hline 42 & Brignole & 1.69 & 10 & 1 \\
\hline 36 & San Nicola & 1.77 & 11 & 1 \\
\hline 68 & Quartara & 1.97 & 12 & 1 \\
\hline 70 & Quinto & 2.08 & 13 & 1 \\
\hline 66 & Sturla & 2.25 & 14 & 2 \\
\hline 7 & Pegli & 2.28 & 15 & 2 \\
\hline 61 & San Martino & 2.59 & 16 & 2 \\
\hline 27 & Belvedere & 2.61 & 17 & 2 \\
\hline 32 & Oregina & 2.68 & 18 & 2 \\
\hline 69 & Castagna & 2.70 & 19 & 2 \\
\hline 71 & Nervi & 2.86 & 20 & 2 \\
\hline 8 & Multedo & 2.87 & 21 & 2 \\
\hline 60 & Chiappeto & 2.88 & 22 & 2 \\
\hline 43 & S. Agata & 2.90 & 23 & 2 \\
\hline 67 & Quarto & 2.98 & 24 & 2 \\
\hline 28 & S. Bartolomeo & 3.01 & 25 & 2 \\
\hline 48 & Forte Quezzi & 3.07 & 26 & 2 \\
\hline 10 & S. G. Battista & 3.07 & 27 & 2 \\
\hline 25 & San Gaetano & 3.09 & 28 & 2 \\
\hline 31 & Lagaccio & 3.10 & 29 & 2 \\
\hline 9 & Sestri & 3.12 & 30 & 2 \\
\hline 30 & San Teodoro & 3.13 & 31 & 2 \\
\hline 56 & Bavari & 3.20 & 32 & 2 \\
\hline 11 & Calcinara & 3.22 & 33 & 2 \\
\hline 59 & Borgoratti & 3.31 & 34 & 2 \\
\hline 44 & S. Fruttuoso & 3.32 & 35 & 2 \\
\hline 46 & Fereggiano & 3.39 & 36 & 3 \\
\hline 1 & Crevari & 3.41 & 37 & 3 \\
\hline 47 & Marassi & 3.41 & 38 & 3 \\
\hline 6 & Castelluccio & 3.42 & 39 & 3 \\
\hline
\end{tabular}


Measuring Change Over Time in Socio-economic Deprivation...

Table 9 continued

\begin{tabular}{|c|c|c|c|c|}
\hline ID & Uus & GDIs score & Ranking & Deprivation class \\
\hline 50 & San Pantaleo & 3.55 & 40 & 3 \\
\hline 51 & Montesignano & 3.60 & 41 & 3 \\
\hline 15 & Rivarolo & 3.65 & 42 & 3 \\
\hline 26 & Sampierdarena & 3.67 & 43 & 3 \\
\hline 58 & Apparizione & 3.71 & 44 & 3 \\
\hline 12 & Borzoli Ovest & 3.72 & 45 & 3 \\
\hline 55 & Prato & 3.73 & 46 & 3 \\
\hline 13 & Borzoli Est & 3.75 & 47 & 3 \\
\hline 21 & Pontedecimo & 3.76 & 48 & 3 \\
\hline 29 & Angeli & 3.77 & 49 & 3 \\
\hline 2 & Voltri & 3.78 & 50 & 3 \\
\hline 34 & Maddalena & 3.92 & 51 & 3 \\
\hline 49 & Parenzo & 3.97 & 52 & 3 \\
\hline 4 & Palmaro & 4.08 & 53 & 3 \\
\hline 57 & S. Desiderio & 4.08 & 54 & 3 \\
\hline 45 & Quezzi & 4.09 & 55 & 3 \\
\hline 24 & Campasso & 4.12 & 56 & 3 \\
\hline 54 & Doria & 4.18 & 57 & 3 \\
\hline 14 & Certosa & 4.20 & 58 & 3 \\
\hline 35 & Molo & 4.21 & 59 & 3 \\
\hline 53 & Molassana & 4.22 & 60 & 3 \\
\hline 22 & Cornigliano & 4.44 & 61 & 4 \\
\hline 19 & Morego & 4.52 & 62 & 4 \\
\hline 23 & Campi & 4.63 & 63 & 4 \\
\hline 20 & S. Quirico & 4.69 & 64 & 4 \\
\hline 16 & Teglia & 4.70 & 65 & 4 \\
\hline 5 & Pra' & 5.07 & 66 & 4 \\
\hline 52 & S. Eusebio & 5.21 & 67 & 4 \\
\hline 33 & Prè & 5.43 & 68 & 5 \\
\hline 17 & Begato & 5.72 & 69 & 5 \\
\hline 18 & Bolzaneto & 6.10 & 70 & 5 \\
\hline 3 & Ca' Nuova & 8.74 & 71 & 6 \\
\hline
\end{tabular}

Table 10 GDIs 2001-DP2 method

\begin{tabular}{lllll}
\hline ID & Uus & GDIs score & Ranking & Deprivation class \\
\hline 64 & Lido & 1.37 & 1 & 1 \\
38 & Manin & 1.38 & 2 & 1 \\
65 & Puggia & 1.39 & 3 & 1 \\
37 & Castelletto & 1.40 & 4 & 1 \\
62 & Albaro & 1.42 & 5 & 1 \\
39 & S. Vincenzo & 1.53 & 6 & 1 \\
\hline
\end{tabular}


S. Landi et al.

Table 10 continued

\begin{tabular}{|c|c|c|c|c|}
\hline ID & Uus & GDIs score & Ranking & Deprivation class \\
\hline 63 & San Giuliano & 1.61 & 7 & 1 \\
\hline 41 & Foce & 1.89 & 8 & 1 \\
\hline 40 & Carignano & 1.89 & 9 & 1 \\
\hline 68 & Quartara & 2.18 & 10 & 1 \\
\hline 36 & San Nicola & 2.19 & 11 & 1 \\
\hline 42 & Brignole & 2.26 & 12 & 1 \\
\hline 70 & Quinto & 2.46 & 13 & 1 \\
\hline 66 & Sturla & 2.82 & 14 & 2 \\
\hline 67 & Quarto & 2.89 & 15 & 2 \\
\hline 61 & San Martino & 2.94 & 16 & 2 \\
\hline 7 & Pegli & 2.98 & 17 & 2 \\
\hline 56 & Bavari & 3.14 & 18 & 2 \\
\hline 8 & Multedo & 3.25 & 19 & 2 \\
\hline 69 & Castagna & 3.26 & 20 & 2 \\
\hline 71 & Nervi & 3.39 & 21 & 2 \\
\hline 27 & Belvedere & 3.39 & 22 & 2 \\
\hline 30 & San Teodoro & 3.41 & 23 & 2 \\
\hline 1 & Crevari & 3.53 & 24 & 2 \\
\hline 58 & Apparizione & 3.53 & 25 & 2 \\
\hline 9 & Sestri & 3.61 & 26 & 2 \\
\hline 25 & San Gaetano & 3.76 & 27 & 2 \\
\hline 47 & Marassi & 3.77 & 28 & 2 \\
\hline 43 & S. Agata & 3.83 & 29 & 2 \\
\hline 26 & Sampierdarena & 3.83 & 30 & 2 \\
\hline 28 & S. Bartolomeo & 3.88 & 31 & 2 \\
\hline 48 & Forte Quezzi & 3.96 & 32 & 2 \\
\hline 31 & Lagaccio & 3.96 & 33 & 2 \\
\hline 60 & Chiappeto & 3.97 & 34 & 2 \\
\hline 32 & Oregina & 4.01 & 35 & 2 \\
\hline 44 & S. Fruttuoso & 4.04 & 36 & 2 \\
\hline 15 & Rivarolo & 4.60 & 37 & 3 \\
\hline 23 & Campi & 4.62 & 38 & 3 \\
\hline 19 & Morego & 4.64 & 39 & 3 \\
\hline 4 & Palmaro & 4.65 & 40 & 3 \\
\hline 11 & Calcinara & 4.65 & 41 & 3 \\
\hline 34 & Maddalena & 4.66 & 42 & 3 \\
\hline 50 & San Pantaleo & 4.73 & 43 & 3 \\
\hline 46 & Fereggiano & 4.74 & 44 & 3 \\
\hline 12 & Borzoli Ovest & 4.75 & 45 & 3 \\
\hline 6 & Castelluccio & 4.75 & 46 & 3 \\
\hline 55 & Prato & 4.80 & 47 & 3 \\
\hline 14 & Certosa & 4.86 & 48 & 3 \\
\hline 59 & Borgoratti & 4.86 & 49 & 3 \\
\hline
\end{tabular}


Measuring Change Over Time in Socio-economic Deprivation...

Table 10 continued

\begin{tabular}{lllll}
\hline ID & Uus & GDIs score & Ranking & Deprivation class \\
\hline 57 & S. Desiderio & 4.89 & 50 & 3 \\
21 & Pontedecimo & 4.90 & 51 & 3 \\
10 & S. G. Battista & 4.94 & 52 & 3 \\
45 & Quezzi & 4.98 & 53 & 3 \\
29 & Angeli & 4.99 & 54 & 3 \\
35 & Molo & 5.07 & 55 & 3 \\
24 & Campasso & 5.22 & 56 & 4 \\
49 & Parenzo & 5.25 & 57 & 4 \\
2 & Voltri & 5.27 & 58 & 4 \\
13 & Borzoli Est & 5.31 & 59 & 4 \\
53 & Molassana & 5.43 & 60 & 4 \\
54 & Doria & 5.53 & 61 & 4 \\
51 & Montesignano & 5.53 & 62 & 4 \\
22 & Cornigliano & 5.61 & 63 & 4 \\
33 & Prè & 5.66 & 64 & 4 \\
20 & S. Quirico & 5.72 & 65 & 4 \\
16 & Teglia & 5.91 & 66 & 4 \\
5 & Pra' & 5.99 & 67 & 5 \\
52 & S. Eusebio & 6.83 & 68 & 5 \\
18 & Bolzaneto & 7.03 & 69 & 5 \\
17 & Begato & 7.07 & 70 & 6 \\
3 & Ca' Nuova & 11.53 & 71 &
\end{tabular}

Table 11 GDIs 1991-DP2 method

\begin{tabular}{lllll}
\hline ID & Uus & GDIs score & Ranking & Deprivation class \\
\hline 39 & S. Vincenzo & 3.27 & 1 & 1 \\
64 & Lido & 3.30 & 2 & 1 \\
62 & Albaro & 3.33 & 3 & 1 \\
65 & Puggia & 3.41 & 4 & 1 \\
38 & Manin & 3.49 & 5 & 1 \\
40 & Carignano & 3.50 & 6 & 1 \\
63 & San Giuliano & 3.65 & 7 & 1 \\
41 & Foce & 3.75 & 8 & 1 \\
37 & Castelletto & 3.75 & 9 & 1 \\
68 & Quartara & 3.99 & 10 & 1 \\
36 & San Nicola & 4.23 & 11 & 2 \\
70 & Quinto & 4.80 & 12 & 2 \\
42 & Brignole & 4.83 & 13 & 2 \\
69 & Castagna & 4.83 & 14 & 2 \\
67 & Quarto & 4.98 & 15 & 2 \\
66 & Sturla & 5.23 & 16 & \\
\hline
\end{tabular}


S. Landi et al.

Table 11 continued

\begin{tabular}{|c|c|c|c|c|}
\hline ID & Uus & GDIs score & Ranking & Deprivation class \\
\hline 7 & Pegli & 5.23 & 17 & 2 \\
\hline 71 & Nervi & 5.25 & 18 & 2 \\
\hline 61 & San Martino & 5.41 & 19 & 2 \\
\hline 8 & Multedo & 5.62 & 20 & 2 \\
\hline 56 & Bavari & 5.75 & 21 & 2 \\
\hline 27 & Belvedere & 5.91 & 22 & 2 \\
\hline 43 & S. Agata & 6.07 & 23 & 2 \\
\hline 58 & Apparizione & 6.09 & 24 & 2 \\
\hline 60 & Chiappeto & 6.18 & 25 & 3 \\
\hline 9 & Sestri & 6.27 & 26 & 3 \\
\hline 28 & S. Bartolomeo & 6.27 & 27 & 3 \\
\hline 44 & S. Fruttuoso & 6.37 & 28 & 3 \\
\hline 1 & Crevari & 6.50 & 29 & 3 \\
\hline 30 & San Teodoro & 6.50 & 30 & 3 \\
\hline 47 & Marassi & 6.56 & 31 & 3 \\
\hline 25 & San Gaetano & 6.59 & 32 & 3 \\
\hline 26 & Sampierdarena & 6.69 & 33 & 3 \\
\hline 48 & Forte Quezzi & 6.81 & 34 & 3 \\
\hline 12 & Borzoli Ovest & 6.84 & 35 & 3 \\
\hline 11 & Calcinara & 6.87 & 36 & 3 \\
\hline 21 & Pontedecimo & 6.89 & 37 & 3 \\
\hline 46 & Fereggiano & 7.00 & 38 & 3 \\
\hline 15 & Rivarolo & 7.05 & 39 & 3 \\
\hline 6 & Castelluccio & 7.13 & 40 & 3 \\
\hline 14 & Certosa & 7.13 & 41 & 3 \\
\hline 10 & S. G. Battista & 7.24 & 42 & 3 \\
\hline 50 & San Pantaleo & 7.44 & 43 & 3 \\
\hline 4 & Palmaro & 7.46 & 44 & 3 \\
\hline 55 & Prato & 7.48 & 45 & 3 \\
\hline 19 & Morego & 7.49 & 46 & 3 \\
\hline 32 & Oregina & 7.50 & 47 & 3 \\
\hline 2 & Voltri & 7.78 & 48 & 4 \\
\hline 31 & Lagaccio & 7.79 & 49 & 4 \\
\hline 13 & Borzoli Est & 7.79 & 50 & 4 \\
\hline 29 & Angeli & 7.82 & 51 & 4 \\
\hline 24 & Campasso & 7.83 & 52 & 4 \\
\hline 57 & S. Desiderio & 7.87 & 53 & 4 \\
\hline 59 & Borgoratti & 7.89 & 54 & 4 \\
\hline 53 & Molassana & 8.14 & 55 & 4 \\
\hline 49 & Parenzo & 8.18 & 56 & 4 \\
\hline 45 & Quezzi & 8.25 & 57 & 4 \\
\hline 5 & Pra' & 8.28 & 58 & 4 \\
\hline 54 & Doria & 8.46 & 59 & 4 \\
\hline
\end{tabular}


Measuring Change Over Time in Socio-economic Deprivation...

Table 11 continued

\begin{tabular}{lllll}
\hline ID & Uus & GDIs score & Ranking & Deprivation class \\
\hline 23 & Campi & 8.50 & 60 & 4 \\
16 & Teglia & 8.65 & 61 & 4 \\
22 & Cornigliano & 8.87 & 62 & 4 \\
51 & Montesignano & 8.92 & 63 & 4 \\
34 & Maddalena & 9.05 & 64 & 4 \\
18 & Bolzaneto & 9.31 & 65 & 5 \\
20 & S. Quirico & 9.64 & 66 & 5 \\
33 & Prè & 9.90 & 67 & 5 \\
35 & Molo & 9.97 & 68 & 5 \\
17 & Begato & 10.46 & 69 & 5 \\
52 & S. Eusebio & 10.51 & 70 & 5 \\
3 & Ca' Nuova & 16.02 & 71 & 6 \\
\hline
\end{tabular}

Table 12 GDIs 2011-additive method

\begin{tabular}{|c|c|c|c|c|}
\hline ID & Uus & GDIs score & Ranking & Deprivation class \\
\hline 39 & S. Vincenzo & -5.75 & 1 & 1 \\
\hline 65 & Puggia & -5.71 & 2 & 1 \\
\hline 40 & Carignano & -5.55 & 3 & 1 \\
\hline 38 & Manin & -5.54 & 4 & 1 \\
\hline 41 & Foce & -5.50 & 5 & 1 \\
\hline 37 & Castelletto & -5.49 & 6 & 1 \\
\hline 63 & San Giuliano & -5.07 & 7 & 1 \\
\hline 62 & Albaro & -5.05 & 8 & 1 \\
\hline 64 & Lido & -5.01 & 9 & 1 \\
\hline 42 & Brignole & -4.92 & 10 & 1 \\
\hline 36 & San Nicola & -4.68 & 11 & 1 \\
\hline 68 & Quartara & -4.20 & 12 & 1 \\
\hline 70 & Quinto & -3.87 & 13 & 1 \\
\hline 66 & Sturla & -3.87 & 14 & 1 \\
\hline 7 & Pegli & -3.64 & 15 & 2 \\
\hline 61 & San Martino & -3.20 & 16 & 2 \\
\hline 43 & S. Agata & -3.00 & 17 & 2 \\
\hline 27 & Belvedere & -2.98 & 18 & 2 \\
\hline 32 & Oregina & -2.94 & 19 & 2 \\
\hline 71 & Nervi & -2.89 & 20 & 2 \\
\hline 69 & Castagna & -2.88 & 21 & 2 \\
\hline 60 & Chiappeto & -2.66 & 22 & 2 \\
\hline 31 & Lagaccio & -2.61 & 23 & 2 \\
\hline 67 & Quarto & -2.57 & 24 & 2 \\
\hline 8 & Multedo & -2.54 & 25 & 2 \\
\hline 9 & Sestri & -2.39 & 26 & 2 \\
\hline
\end{tabular}


S. Landi et al.

Table 12 continued

\begin{tabular}{|c|c|c|c|c|}
\hline ID & Uus & GDIs score & Ranking & Deprivation class \\
\hline 25 & San Gaetano & -2.37 & 27 & 2 \\
\hline 28 & S. Bartolomeo & -2.35 & 28 & 2 \\
\hline 48 & Forte Quezzi & -2.33 & 29 & 2 \\
\hline 30 & San Teodoro & -2.31 & 30 & 2 \\
\hline 10 & S. G. Battista & -2.22 & 31 & 2 \\
\hline 56 & Bavari & -2.13 & 32 & 2 \\
\hline 44 & S. Fruttuoso & -2.04 & 33 & 2 \\
\hline 11 & Calcinara & -2.03 & 34 & 2 \\
\hline 6 & Castelluccio & -1.98 & 35 & 2 \\
\hline 47 & Marassi & -1.95 & 36 & 2 \\
\hline 59 & Borgoratti & -1.90 & 37 & 2 \\
\hline 34 & Maddalena & -1.84 & 38 & 3 \\
\hline 46 & Fereggiano & -1.77 & 39 & 3 \\
\hline 51 & Montesignano & -1.68 & 40 & 3 \\
\hline 50 & San Pantaleo & -1.60 & 41 & 3 \\
\hline 26 & Sampierdarena & -1.55 & 42 & 3 \\
\hline 1 & Crevari & -1.54 & 43 & 3 \\
\hline 58 & Apparizione & -1.47 & 44 & 3 \\
\hline 21 & Pontedecimo & -1.39 & 45 & 3 \\
\hline 29 & Angeli & -1.35 & 46 & 3 \\
\hline 2 & Voltri & -1.32 & 47 & 3 \\
\hline 15 & Rivarolo & -1.30 & 48 & 3 \\
\hline 13 & Borzoli Est & -1.27 & 49 & 3 \\
\hline 12 & Borzoli Ovest & -1.20 & 50 & 3 \\
\hline 35 & Molo & -1.20 & 51 & 3 \\
\hline 55 & Prato & -1.15 & 52 & 3 \\
\hline 49 & Parenzo & -0.95 & 53 & 3 \\
\hline 57 & S. Desiderio & -0.75 & 54 & 3 \\
\hline 24 & Campasso & -0.65 & 55 & 3 \\
\hline 53 & Molassana & -0.60 & 56 & 3 \\
\hline 45 & Quezzi & -0.52 & 57 & 3 \\
\hline 14 & Certosa & -0.52 & 58 & 3 \\
\hline 4 & Palmaro & -0.47 & 59 & 3 \\
\hline 54 & Doria & -0.45 & 60 & 3 \\
\hline 22 & Cornigliano & -0.25 & 61 & 4 \\
\hline 19 & Morego & 0.12 & 62 & 4 \\
\hline 20 & S. Quirico & 0.26 & 63 & 4 \\
\hline 23 & Campi & 0.38 & 64 & 4 \\
\hline 16 & Teglia & 0.40 & 65 & 4 \\
\hline 5 & Pra' & 0.54 & 66 & 4 \\
\hline 33 & Prè & 0.56 & 67 & 4 \\
\hline 52 & S. Eusebio & 0.90 & 68 & 5 \\
\hline 17 & Begato & 1.73 & 69 & 5 \\
\hline
\end{tabular}


Measuring Change Over Time in Socio-economic Deprivation...

Table 12 continued

\begin{tabular}{lllll}
\hline ID & Uus & GDIs score & Ranking & Deprivation class \\
\hline 18 & Bolzaneto & 1.95 & 70 & 5 \\
3 & Ca' Nuova & 5.29 & 71 & 6 \\
\hline
\end{tabular}

Table 13 GDIs 2001-additive method

\begin{tabular}{|c|c|c|c|c|}
\hline ID & Uus & GDIs score & Ranking & Deprivation class \\
\hline 37 & Castelletto & -5.41 & 1 & 1 \\
\hline 38 & Manin & -5.40 & 2 & 1 \\
\hline 62 & Albaro & -5.33 & 3 & 1 \\
\hline 65 & Puggia & -5.31 & 4 & 1 \\
\hline 64 & Lido & -5.27 & 5 & 1 \\
\hline 39 & S. Vincenzo & -5.16 & 6 & 1 \\
\hline 63 & San Giuliano & -4.98 & 7 & 1 \\
\hline 40 & Carignano & -4.77 & 8 & 1 \\
\hline 41 & Foce & -4.49 & 9 & 1 \\
\hline 42 & Brignole & -4.10 & 10 & 1 \\
\hline 36 & San Nicola & -3.99 & 11 & 1 \\
\hline 68 & Quartara & -3.95 & 12 & 1 \\
\hline 70 & Quinto & -3.24 & 13 & 1 \\
\hline 66 & Sturla & -2.77 & 14 & 2 \\
\hline 67 & Quarto & -2.74 & 15 & 2 \\
\hline 61 & San Martino & -2.64 & 16 & 2 \\
\hline 7 & Pegli & -2.47 & 17 & 2 \\
\hline 71 & Nervi & -2.09 & 18 & 2 \\
\hline 69 & Castagna & -2.04 & 19 & 2 \\
\hline 8 & Multedo & -1.79 & 20 & 2 \\
\hline 27 & Belvedere & -1.73 & 21 & 2 \\
\hline 56 & Bavari & -1.69 & 22 & 2 \\
\hline 30 & San Teodoro & -1.68 & 23 & 2 \\
\hline 9 & Sestri & -1.52 & 24 & 2 \\
\hline 43 & S. Agata & -1.47 & 25 & 2 \\
\hline 26 & Sampierdarena & -1.46 & 26 & 2 \\
\hline 25 & San Gaetano & -1.42 & 27 & 2 \\
\hline 58 & Apparizione & -1.39 & 28 & 2 \\
\hline 1 & Crevari & -1.37 & 29 & 2 \\
\hline 47 & Marassi & -1.32 & 30 & 2 \\
\hline 28 & S. Bartolomeo & -1.08 & 31 & 2 \\
\hline 31 & Lagaccio & -1.02 & 32 & 2 \\
\hline 60 & Chiappeto & -0.96 & 33 & 2 \\
\hline 44 & S. Fruttuoso & -0.93 & 34 & 2 \\
\hline 48 & Forte Quezzi & -0.81 & 35 & 2 \\
\hline 34 & Maddalena & -0.71 & 36 & 2 \\
\hline 32 & Oregina & -0.69 & 37 & 2 \\
\hline
\end{tabular}


S. Landi et al.

Table 13 continued

\begin{tabular}{|c|c|c|c|c|}
\hline ID & Uus & GDIs score & Ranking & Deprivation class \\
\hline 6 & Castelluccio & -0.01 & 38 & 3 \\
\hline 15 & Rivarolo & 0.10 & 39 & 3 \\
\hline 46 & Fereggiano & 0.14 & 40 & 3 \\
\hline 11 & Calcinara & 0.15 & 41 & 3 \\
\hline 35 & Molo & 0.17 & 42 & 3 \\
\hline 19 & Morego & 0.20 & 43 & 3 \\
\hline 50 & San Pantaleo & 0.29 & 44 & 3 \\
\hline 12 & Borzoli Ovest & 0.31 & 45 & 3 \\
\hline 14 & Certosa & 0.31 & 46 & 3 \\
\hline 4 & Palmaro & 0.40 & 47 & 3 \\
\hline 10 & S. G. Battista & 0.44 & 48 & 3 \\
\hline 23 & Campi & 0.44 & 49 & 3 \\
\hline 55 & Prato & 0.45 & 50 & 3 \\
\hline 21 & Pontedecimo & 0.49 & 51 & 3 \\
\hline 29 & Angeli & 0.53 & 52 & 3 \\
\hline 59 & Borgoratti & 0.60 & 53 & 3 \\
\hline 57 & S. Desiderio & 0.70 & 54 & 3 \\
\hline 33 & Prè & 0.81 & 55 & 3 \\
\hline 45 & Quezzi & 0.87 & 56 & 3 \\
\hline 24 & Campasso & 0.89 & 57 & 3 \\
\hline 49 & Parenzo & 1.03 & 58 & 4 \\
\hline 2 & Voltri & 1.04 & 59 & 4 \\
\hline 13 & Borzoli Est & 1.25 & 60 & 4 \\
\hline 22 & Cornigliano & 1.42 & 61 & 4 \\
\hline 54 & Doria & 1.56 & 62 & 4 \\
\hline 53 & Molassana & 1.57 & 63 & 4 \\
\hline 20 & S. Quirico & 1.66 & 64 & 4 \\
\hline 51 & Montesignano & 1.73 & 65 & 4 \\
\hline 16 & Teglia & 1.91 & 66 & 4 \\
\hline 5 & Pra' & 1.97 & 67 & 4 \\
\hline 18 & Bolzaneto & 3.26 & 68 & 5 \\
\hline 52 & S. Eusebio & 3.53 & 69 & 5 \\
\hline 17 & Begato & 3.81 & 70 & 5 \\
\hline 3 & Ca' Nuova & 9.64 & 71 & 6 \\
\hline
\end{tabular}


Table 14 GDIs 1991-additive method

\begin{tabular}{|c|c|c|c|c|}
\hline ID & Uus & GDIs score & Ranking & Deprivation class \\
\hline 39 & S. Vincenzo & -2.75 & 1 & 1 \\
\hline 64 & Lido & -2.62 & 2 & 1 \\
\hline 62 & Albaro & -2.55 & 3 & 1 \\
\hline 38 & Manin & -2.55 & 4 & 1 \\
\hline 65 & Puggia & -2.49 & 5 & 1 \\
\hline 40 & Carignano & -2.44 & 6 & 1 \\
\hline 37 & Castelletto & -2.12 & 7 & 1 \\
\hline 63 & San Giuliano & -2.08 & 8 & 1 \\
\hline 41 & Foce & -1.91 & 9 & 1 \\
\hline 68 & Quartara & -1.39 & 10 & 1 \\
\hline 36 & San Nicola & -1.11 & 11 & 1 \\
\hline 42 & Brignole & -0.45 & 12 & 2 \\
\hline 70 & Quinto & -0.01 & 13 & 2 \\
\hline 69 & Castagna & 0.15 & 14 & 2 \\
\hline 67 & Quarto & 0.15 & 15 & 2 \\
\hline 7 & Pegli & 0.54 & 16 & 2 \\
\hline 66 & Sturla & 0.56 & 17 & 2 \\
\hline 71 & Nervi & 0.61 & 18 & 2 \\
\hline 61 & San Martino & 0.78 & 19 & 2 \\
\hline 8 & Multedo & 1.38 & 20 & 2 \\
\hline 43 & S. Agata & 1.59 & 21 & 2 \\
\hline 27 & Belvedere & 1.75 & 22 & 2 \\
\hline 56 & Bavari & 1.76 & 23 & 2 \\
\hline 9 & Sestri & 1.95 & 24 & 3 \\
\hline 58 & Apparizione & 1.98 & 25 & 3 \\
\hline 60 & Chiappeto & 2.18 & 26 & 3 \\
\hline 28 & S. Bartolomeo & 2.22 & 27 & 3 \\
\hline 26 & Sampierdarena & 2.26 & 28 & 3 \\
\hline 44 & S. Fruttuoso & 2.37 & 29 & 3 \\
\hline 30 & San Teodoro & 2.39 & 30 & 3 \\
\hline 25 & San Gaetano & 2.40 & 31 & 3 \\
\hline 1 & Crevari & 2.41 & 32 & 3 \\
\hline 47 & Marassi & 2.46 & 33 & 3 \\
\hline 48 & Forte Quezzi & 2.97 & 34 & 3 \\
\hline 6 & Castelluccio & 3.11 & 35 & 3 \\
\hline 11 & Calcinara & 3.26 & 36 & 3 \\
\hline 21 & Pontedecimo & 3.29 & 37 & 3 \\
\hline 46 & Fereggiano & 3.34 & 38 & 3 \\
\hline 15 & Rivarolo & 3.35 & 39 & 3 \\
\hline 14 & Certosa & 3.40 & 40 & 3 \\
\hline 12 & Borzoli Ovest & 3.40 & 41 & 3 \\
\hline 10 & S. G. Battista & 3.67 & 42 & 3 \\
\hline 32 & Oregina & 3.93 & 43 & 3 \\
\hline
\end{tabular}


S. Landi et al.

Table 14 continued

\begin{tabular}{|c|c|c|c|c|}
\hline ID & Uus & GDIs score & Ranking & Deprivation class \\
\hline 19 & Morego & 3.97 & 44 & 3 \\
\hline 31 & Lagaccio & 3.99 & 45 & 3 \\
\hline 50 & San Pantaleo & 4.00 & 46 & 3 \\
\hline 55 & Prato & 4.04 & 47 & 3 \\
\hline 4 & Palmaro & 4.08 & 48 & 3 \\
\hline 29 & Angeli & 4.25 & 49 & 4 \\
\hline 24 & Campasso & 4.32 & 50 & 4 \\
\hline 2 & Voltri & 4.49 & 51 & 4 \\
\hline 57 & S. Desiderio & 4.51 & 52 & 4 \\
\hline 13 & Borzoli Est & 4.65 & 53 & 4 \\
\hline 59 & Borgoratti & 4.69 & 54 & 4 \\
\hline 34 & Maddalena & 4.95 & 55 & 4 \\
\hline 49 & Parenzo & 5.00 & 56 & 4 \\
\hline 5 & Pra' & 5.07 & 57 & 4 \\
\hline 23 & Campi & 5.14 & 58 & 4 \\
\hline 45 & Quezzi & 5.23 & 59 & 4 \\
\hline 53 & Molassana & 5.34 & 60 & 4 \\
\hline 16 & Teglia & 5.50 & 61 & 4 \\
\hline 22 & Cornigliano & 5.60 & 62 & 4 \\
\hline 54 & Doria & 5.62 & 63 & 4 \\
\hline 33 & Prè & 5.74 & 64 & 4 \\
\hline 35 & Molo & 6.20 & 65 & 5 \\
\hline 51 & Montesignano & 6.21 & 66 & 5 \\
\hline 18 & Bolzaneto & 6.33 & 67 & 5 \\
\hline 20 & S. Quirico & 6.70 & 68 & 5 \\
\hline 52 & S. Eusebio & 8.15 & 69 & 5 \\
\hline 17 & Begato & 8.20 & 70 & 5 \\
\hline 3 & Ca' Nuova & 15.26 & 71 & 6 \\
\hline
\end{tabular}

Table 15 GDIs 2011-MPI

\begin{tabular}{lllll}
\hline ID & Uus & GDIs score & Ranking & Deprivation class \\
\hline 39 & S. Vincenzo & 84.51 & 1 & 1 \\
65 & Puggia & 84.86 & 2 & 1 \\
40 & Carignano & 85.08 & 3 & 1 \\
38 & Manin & 85.11 & 4 & 1 \\
41 & Foce & 85.60 & 5 & 1 \\
37 & Castelletto & 85.60 & 6 & 1 \\
64 & Lido & 86.38 & 7 & 1 \\
63 & San Giuliano & 86.38 & 8 & 1 \\
62 & Albaro & 86.67 & 9 & 1 \\
42 & Brignole & 87.14 & 10 & 1 \\
\hline
\end{tabular}


Measuring Change Over Time in Socio-economic Deprivation...

Table 15 continued

\begin{tabular}{|c|c|c|c|c|}
\hline ID & Uus & GDIs score & Ranking & Deprivation class \\
\hline 36 & San Nicola & 87.98 & 11 & 1 \\
\hline 68 & Quartara & 89.13 & 12 & 1 \\
\hline 66 & Sturla & 89.94 & 13 & 1 \\
\hline 70 & Quinto & 90.14 & 14 & 1 \\
\hline 7 & Pegli & 90.80 & 15 & 1 \\
\hline 61 & San Martino & 91.82 & 16 & 2 \\
\hline 43 & S. Agata & 92.08 & 17 & 2 \\
\hline 71 & Nervi & 92.28 & 18 & 2 \\
\hline 27 & Belvedere & 92.43 & 19 & 2 \\
\hline 69 & Castagna & 92.48 & 20 & 2 \\
\hline 32 & Oregina & 92.55 & 21 & 2 \\
\hline 34 & Maddalena & 93.05 & 22 & 2 \\
\hline 67 & Quarto & 93.28 & 23 & 2 \\
\hline 60 & Chiappeto & 93.34 & 24 & 2 \\
\hline 31 & Lagaccio & 93.42 & 25 & 2 \\
\hline 8 & Multedo & 93.54 & 26 & 2 \\
\hline 9 & Sestri & 94.00 & 27 & 2 \\
\hline 25 & San Gaetano & 94.03 & 28 & 2 \\
\hline 28 & S. Bartolomeo & 94.05 & 29 & 2 \\
\hline 48 & Forte Quezzi & 94.15 & 30 & 2 \\
\hline 30 & San Teodoro & 94.20 & 31 & 2 \\
\hline 10 & S. G. Battista & 94.35 & 32 & 2 \\
\hline 56 & Bavari & 94.43 & 33 & 2 \\
\hline 6 & Castelluccio & 94.73 & 34 & 2 \\
\hline 11 & Calcinara & 94.79 & 35 & 2 \\
\hline 47 & Marassi & 94.83 & 36 & 2 \\
\hline 44 & S. Fruttuoso & 94.83 & 37 & 2 \\
\hline 35 & Molo & 94.98 & 38 & 2 \\
\hline 59 & Borgoratti & 95.12 & 39 & 2 \\
\hline 46 & Fereggiano & 95.50 & 40 & 3 \\
\hline 51 & Montesignano & 95.58 & 41 & 3 \\
\hline 1 & Crevari & 95.89 & 42 & 3 \\
\hline 50 & San Pantaleo & 95.94 & 43 & 3 \\
\hline 26 & Sampierdarena & 96.01 & 44 & 3 \\
\hline 58 & Apparizione & 96.18 & 45 & 3 \\
\hline 21 & Pontedecimo & 96.34 & 46 & 3 \\
\hline 13 & Borzoli Est & 96.37 & 47 & 3 \\
\hline 2 & Voltri & 96.49 & 48 & 3 \\
\hline 29 & Angeli & 96.60 & 49 & 3 \\
\hline 15 & Rivarolo & 96.61 & 50 & 3 \\
\hline 12 & Borzoli Ovest & 96.85 & 51 & 3 \\
\hline 55 & Prato & 96.95 & 52 & 3 \\
\hline 49 & Parenzo & 97.55 & 53 & 3 \\
\hline
\end{tabular}


S. Landi et al.

Table 15 continued

\begin{tabular}{lllll}
\hline ID & Uus & GDIs score & Ranking & Deprivation class \\
\hline 57 & S. Desiderio & 97.96 & 54 & 3 \\
33 & Prè & 98.12 & 55 & 3 \\
53 & Molassana & 98.22 & 56 & 3 \\
24 & Campasso & 98.28 & 57 & 3 \\
4 & Palmaro & 98.35 & 58 & 3 \\
45 & Quezzi & 98.47 & 59 & 3 \\
14 & Certosa & 98.56 & 60 & 3 \\
54 & Doria & 98.68 & 61 & 3 \\
22 & Cornigliano & 99.30 & 62 & 4 \\
19 & Morego & 100.03 & 63 & 4 \\
20 & S. Quirico & 100.28 & 64 & 4 \\
23 & Campi & 100.63 & 65 & 4 \\
16 & Teglia & 100.73 & 66 & 4 \\
5 & Pra' & 101.04 & 67 & 4 \\
52 & S. Eusebio & 102.03 & 68 & 5 \\
17 & Begato & 103.99 & 69 & 5 \\
18 & Bolzaneto & 104.14 & 70 & 5 \\
3 & Ca' Nuova & 110.02 & 71 & 6 \\
\hline
\end{tabular}

Table 16 GDIs 2001-MPI

\begin{tabular}{|c|c|c|c|c|}
\hline ID & Uus & GDIs score & Ranking & Deprivation class \\
\hline 38 & Manin & 86.19123 & 1 & 1 \\
\hline 37 & Castelletto & 86.2132 & 2 & 1 \\
\hline 65 & Puggia & 86.36225 & 3 & 1 \\
\hline 62 & Albaro & 86.41831 & 4 & 1 \\
\hline 64 & Lido & 86.52284 & 5 & 1 \\
\hline 39 & S. Vincenzo & 86.61558 & 6 & 1 \\
\hline 63 & San Giuliano & 87.3404 & 7 & 1 \\
\hline 40 & Carignano & 87.70834 & 8 & 1 \\
\hline 41 & Foce & 88.66877 & 9 & 1 \\
\hline 42 & Brignole & 89.53541 & 10 & 1 \\
\hline 36 & San Nicola & 89.941 & 11 & 1 \\
\hline 68 & Quartara & 89.95276 & 12 & 1 \\
\hline 70 & Quinto & 91.6009 & 13 & 1 \\
\hline 66 & Sturla & 93.0535 & 14 & 2 \\
\hline 67 & Quarto & 93.12995 & 15 & 2 \\
\hline 61 & San Martino & 93.37166 & 16 & 2 \\
\hline 7 & Pegli & 93.72695 & 17 & 2 \\
\hline 69 & Castagna & 94.63964 & 18 & 2 \\
\hline 71 & Nervi & 94.73069 & 19 & 2 \\
\hline 56 & Bavari & 94.74704 & 20 & 2 \\
\hline 8 & Multedo & 94.77851 & 21 & 2 \\
\hline
\end{tabular}


Measuring Change Over Time in Socio-economic Deprivation...

Table 16 continued

\begin{tabular}{|c|c|c|c|c|}
\hline ID & Uus & GDIs score & Ranking & Deprivation class \\
\hline 27 & Belvedere & 95.46265 & 22 & 2 \\
\hline 30 & San Teodoro & 95.51056 & 23 & 2 \\
\hline 9 & Sestri & 95.84295 & 24 & 2 \\
\hline 1 & Crevari & 96.03831 & 25 & 2 \\
\hline 26 & Sampierdarena & 96.1332 & 26 & 2 \\
\hline 25 & San Gaetano & 96.1547 & 27 & 2 \\
\hline 58 & Apparizione & 96.23269 & 28 & 2 \\
\hline 43 & S. Agata & 96.30877 & 29 & 2 \\
\hline 47 & Marassi & 96.53391 & 30 & 2 \\
\hline 28 & S. Bartolomeo & 96.78499 & 31 & 2 \\
\hline 31 & Lagaccio & 96.89583 & 32 & 2 \\
\hline 48 & Forte Quezzi & 97.30769 & 33 & 2 \\
\hline 44 & S. Fruttuoso & 97.49133 & 34 & 2 \\
\hline 32 & Oregina & 97.49884 & 35 & 2 \\
\hline 60 & Chiappeto & 97.50735 & 36 & 2 \\
\hline 34 & Maddalena & 97.576 & 37 & 2 \\
\hline 11 & Calcinara & 99.56249 & 38 & 3 \\
\hline 15 & Rivarolo & 99.71784 & 39 & 3 \\
\hline 6 & Castelluccio & 99.91957 & 40 & 3 \\
\hline 19 & Morego & 99.95935 & 41 & 3 \\
\hline 46 & Fereggiano & 100.0165 & 42 & 3 \\
\hline 23 & Campi & 100.1029 & 43 & 3 \\
\hline 35 & Molo & 100.1656 & 44 & 3 \\
\hline 12 & Borzoli Ovest & 100.238 & 45 & 3 \\
\hline 14 & Certosa & 100.3478 & 46 & 3 \\
\hline 4 & Palmaro & 100.3811 & 47 & 3 \\
\hline 50 & San Pantaleo & 100.4494 & 48 & 3 \\
\hline 55 & Prato & 100.6316 & 49 & 3 \\
\hline 10 & S. G. Battista & 100.9279 & 50 & 3 \\
\hline 21 & Pontedecimo & 101.0473 & 51 & 3 \\
\hline 33 & Prè & 101.1753 & 52 & 3 \\
\hline 29 & Angeli & 101.2152 & 53 & 3 \\
\hline 59 & Borgoratti & 101.2237 & 54 & 3 \\
\hline 57 & S. Desiderio & 101.2316 & 55 & 3 \\
\hline 24 & Campasso & 101.5396 & 56 & 3 \\
\hline 45 & Quezzi & 101.5638 & 57 & 3 \\
\hline 49 & Parenzo & 102.2832 & 58 & 4 \\
\hline 2 & Voltri & 102.472 & 59 & 4 \\
\hline 13 & Borzoli Est & 102.6343 & 60 & 4 \\
\hline 22 & Cornigliano & 103.1811 & 61 & 4 \\
\hline 53 & Molassana & 103.5233 & 62 & 4 \\
\hline 54 & Doria & 103.6095 & 63 & 4 \\
\hline 51 & Montesignano & 103.7914 & 64 & 4 \\
\hline
\end{tabular}


S. Landi et al.

Table 16 continued

\begin{tabular}{lllll}
\hline ID & Uus & GDIs score & Ranking & Deprivation class \\
\hline 20 & S. Quirico & 103.9218 & 65 & 4 \\
16 & Teglia & 104.4777 & 66 & 4 \\
5 & Pra' & 104.8665 & 67 & 4 \\
18 & Bolzaneto & 108.1063 & 68 & 5 \\
52 & S. Eusebio & 108.3102 & 69 & 5 \\
17 & Begato & 109.2278 & 70 & 5 \\
3 & Ca' Nuova & 122.0673 & 71 & 6 \\
\hline
\end{tabular}

Table 17 GDIs 1991-MPI

\begin{tabular}{|c|c|c|c|c|}
\hline ID & Uus & GDIs score & Ranking & Deprivation class \\
\hline 39 & S. Vincenzo & 92.0173 & 1 & 1 \\
\hline 38 & Manin & 93.02349 & 2 & 1 \\
\hline 64 & Lido & 93.1063 & 3 & 1 \\
\hline 62 & Albaro & 93.32812 & 4 & 1 \\
\hline 40 & Carignano & 93.33491 & 5 & 1 \\
\hline 65 & Puggia & 93.33621 & 6 & 1 \\
\hline 37 & Castelletto & 94.21924 & 7 & 1 \\
\hline 63 & San Giuliano & 94.45491 & 8 & 1 \\
\hline 41 & Foce & 94.93614 & 9 & 1 \\
\hline 68 & Quartara & 96.34799 & 10 & 1 \\
\hline 36 & San Nicola & 97.08989 & 11 & 1 \\
\hline 42 & Brignole & 98.39882 & 12 & 1 \\
\hline 70 & Quinto & 99.90015 & 13 & 2 \\
\hline 69 & Castagna & 100.0086 & 14 & 2 \\
\hline 67 & Quarto & 100.3483 & 15 & 2 \\
\hline 7 & Pegli & 101.3315 & 16 & 2 \\
\hline 66 & Sturla & 101.3754 & 17 & 2 \\
\hline 71 & Nervi & 101.4963 & 18 & 2 \\
\hline 61 & San Martino & 101.8796 & 19 & 2 \\
\hline 8 & Multedo & 103.1562 & 20 & 2 \\
\hline 56 & Bavari & 103.7485 & 21 & 2 \\
\hline 43 & S. Agata & 103.8034 & 22 & 2 \\
\hline 27 & Belvedere & 104.2386 & 23 & 2 \\
\hline 9 & Sestri & 104.526 & 24 & 2 \\
\hline 58 & Apparizione & 104.7956 & 25 & 2 \\
\hline 28 & S. Bartolomeo & 105.1542 & 26 & 3 \\
\hline 26 & Sampierdarena & 105.155 & 27 & 3 \\
\hline 60 & Chiappeto & 105.3822 & 28 & 3 \\
\hline 1 & Crevari & 105.6119 & 29 & 3 \\
\hline 25 & San Gaetano & 105.7109 & 30 & 3 \\
\hline 30 & San Teodoro & 105.7502 & 31 & 3 \\
\hline 44 & S. Fruttuoso & 105.8422 & 32 & 3 \\
\hline
\end{tabular}


Measuring Change Over Time in Socio-economic Deprivation...

Table 17 continued

\begin{tabular}{|c|c|c|c|c|}
\hline ID & Uus & GDIs score & Ranking & Deprivation class \\
\hline 47 & Marassi & 106.0394 & 33 & 3 \\
\hline 48 & Forte Quezzi & 106.9164 & 34 & 3 \\
\hline 6 & Castelluccio & 107.578 & 35 & 3 \\
\hline 11 & Calcinara & 107.6036 & 36 & 3 \\
\hline 15 & Rivarolo & 107.9659 & 37 & 3 \\
\hline 21 & Pontedecimo & 108.0735 & 38 & 3 \\
\hline 12 & Borzoli Ovest & 108.1386 & 39 & 3 \\
\hline 46 & Fereggiano & 108.1772 & 40 & 3 \\
\hline 14 & Certosa & 108.2866 & 41 & 3 \\
\hline 10 & S. G. Battista & 109.0994 & 42 & 4 \\
\hline 31 & Lagaccio & 109.3833 & 43 & 4 \\
\hline 32 & Oregina & 109.6399 & 44 & 4 \\
\hline 34 & Maddalena & 109.7363 & 45 & 4 \\
\hline 19 & Morego & 109.7414 & 46 & 4 \\
\hline 55 & Prato & 109.7726 & 47 & 4 \\
\hline 4 & Palmaro & 109.9246 & 48 & 4 \\
\hline 50 & San Pantaleo & 109.9463 & 49 & 4 \\
\hline 24 & Campasso & 110.4548 & 50 & 4 \\
\hline 29 & Angeli & 110.5199 & 51 & 4 \\
\hline 57 & S. Desiderio & 110.9116 & 52 & 4 \\
\hline 2 & Voltri & 111.2134 & 53 & 4 \\
\hline 13 & Borzoli Est & 111.3567 & 54 & 4 \\
\hline 33 & Prè & 111.5919 & 55 & 4 \\
\hline 59 & Borgoratti & 111.6173 & 56 & 4 \\
\hline 23 & Campi & 112.3251 & 57 & 4 \\
\hline 49 & Parenzo & 112.4493 & 58 & 4 \\
\hline 5 & Pra' & 112.6254 & 59 & 4 \\
\hline 45 & Quezzi & 112.6341 & 60 & 4 \\
\hline 53 & Molassana & 113.2119 & 61 & 5 \\
\hline 16 & Teglia & 113.6045 & 62 & 5 \\
\hline 35 & Molo & 113.7201 & 63 & 5 \\
\hline 22 & Cornigliano & 113.7557 & 64 & 5 \\
\hline 54 & Doria & 113.8398 & 65 & 5 \\
\hline 51 & Montesignano & 115.3899 & 66 & 5 \\
\hline 18 & Bolzaneto & 115.7156 & 67 & 5 \\
\hline 20 & S. Quirico & 116.4714 & 68 & 5 \\
\hline 52 & S. Eusebio & 120.046 & 69 & 5 \\
\hline 17 & Begato & 120.2086 & 70 & 5 \\
\hline 3 & Ca' Nuova & 135.0561 & 71 & 6 \\
\hline
\end{tabular}




\section{Appendix 3}

See Fig. 6.

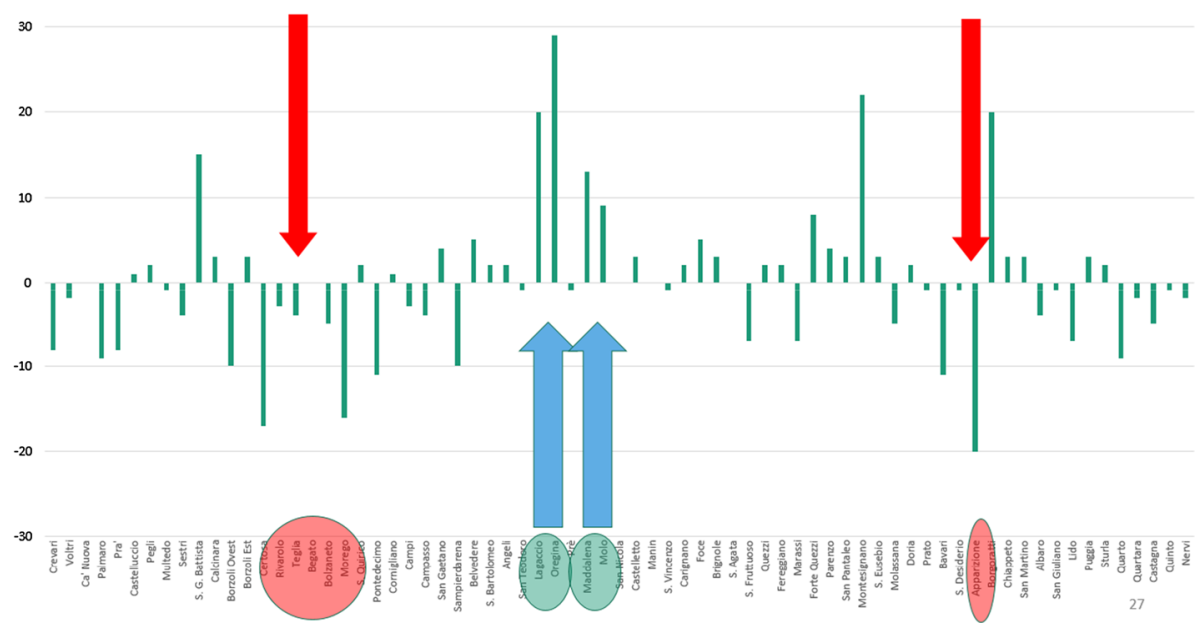

Fig. 6 UUs rankings. Differences in rank for each UUs from 1991 to 2011

\section{Appendix 4}

See Table 18.

Table 18 Test di Friedman

\begin{tabular}{lr}
\hline Test di Friedman & \\
\hline Number & 71 \\
Chi-quadrato & 131,014 \\
df & 2 \\
Sig. Asint. & 0 \\
\hline
\end{tabular}




\section{Appendix 5}

See Figs. 7 and 8.

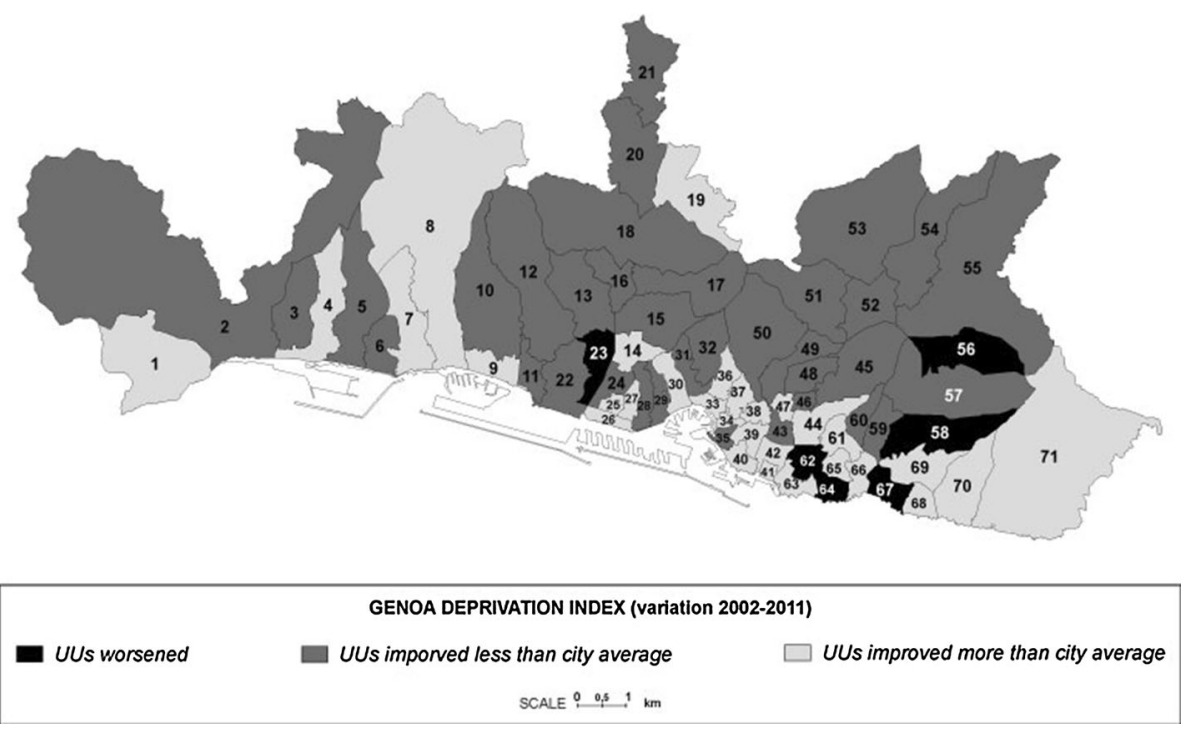

Fig. 7 GDIs scores improvement with respect to the global Genoa improvement for each UUs. 1991-2001

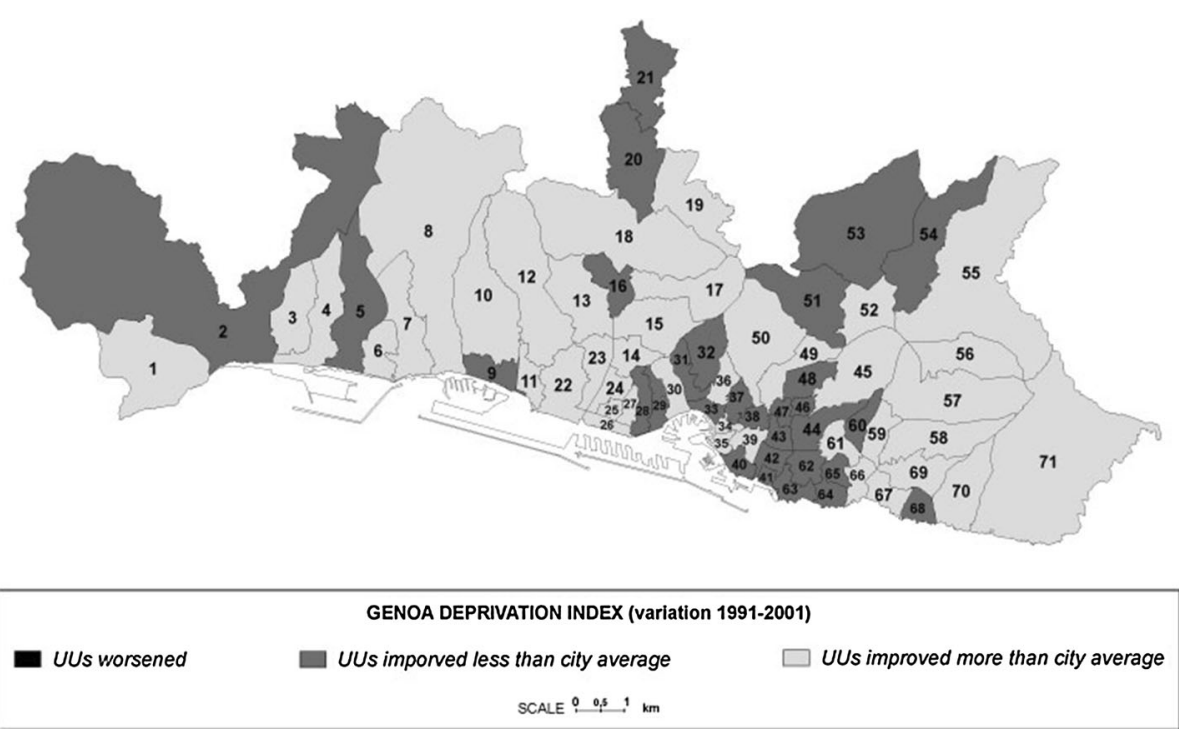

Fig. 8 GDIs scores improvement with respect to the global Genoa improvement for each UUs. 2001-2011 


\section{Appendix 6}

See Table 19.

Table 19 Inhabitants for deprivation classes

\begin{tabular}{|c|c|c|c|c|c|c|c|}
\hline \multirow[t]{2}{*}{ Class number } & \multirow[t]{2}{*}{ Definition } & \multicolumn{2}{|l|}{1991} & \multicolumn{2}{|l|}{2001} & \multicolumn{2}{|l|}{2011} \\
\hline & & Inhabitants & $\%$ & Inhabitants & $\%$ & Inhabitants & $\%$ \\
\hline 1 & \multirow[t]{5}{*}{ Very affluent } & 68,963 & 0.13 & 75,351 & 0.16 & 68,136 & 0.16 \\
\hline 2 & & 91,368 & 0.17 & 168,032 & 0.37 & 162,739 & 0.38 \\
\hline 3 & & 196,050 & 0.37 & 109,454 & 0.26 & 144,290 & 0.34 \\
\hline 4 & & 135,180 & 0.25 & 79,073 & 0.17 & 27,096 & 0.06 \\
\hline 5 & & 36,531 & 0.07 & 16,509 & 0.03 & 19,665 & 0.05 \\
\hline \multirow[t]{2}{*}{6} & High deprivation & 6846 & 0.01 & 5705 & 0.01 & 4740 & 0.01 \\
\hline & Total & 534,938 & 1 & 454,124 & 1 & 426,666 & 1 \\
\hline
\end{tabular}

\section{References}

Adler, E. A., \& Newman, K. (2002). Socioeconomic disparities in health: Pathways and policies. Health Affairs, 21(2), 60-76.

Allik, M., Brown, D., Dundas, R., \& Leyland, A. H. (2016). Developing a new small-area measure of deprivation using 2001 and 2011 census data from Scotland. Health \& Place, 39, 122-130.

Andersen, K. K., Steding-Jessen, M., Dalton, S. O., \& Olsen, T. S. (2014). Socioeconomic position and incidence of ischemic stroke in Denmark 2003-2012: A nationwide hospital-based study. Journal of the American Heart Association, 3(4), 1-6.

Atkinson, J., Salmond, C., \& Crampton, P. (2014). NZDep2013 index of deprivation. Wellington: The Department of Public Health, University of Otago.

Barnett, S., Roderick, P., Martin, D., \& Diamond, I. (2001). A multilevel analysis of the effects of rurality and social deprivation on premature limiting long term illness. Journal of Epidemiology Community Health, 55(1), 44-51.

Bartley, M., \& Blane, D. (1994). Commentary: Appropriateness of deprivation indices must be ensured. BMJ, 309(6967), 1479.

Basta, N. O., James, P. W., Gomez-Pozo, B., Craft, A. W., Norman, P. D., \& McNally, R. J. Q. (2014). Survival from teenage and young adult cancer in northern England, 1968-2008. Pediatric Blood \& Cancer, 61(5), 901-906.

Bell, N., \& Hayes, M. V. (2012). The Vancouver area neighbourhood deprivation index (VANDIX): A census-based tool for assessing small-area variations in health status. Canadian Journal Public Health/ Revue Canadienne de Sante'e Publique, 103(8 Suppl. 2), S28-S32.

Benach, J., \& Yasui, Y. (1999). Geographical patterns of excess mortality in Spain explained by two indices of deprivation. Journal of Epidemiology and Community Health, 53(7), 423-431.

Bertin, M., Chevrier, C., Pelé, F., Serrano-Chavez, T., Cordier, S., \& Viel, J. F. (2014). Can a deprivation index be used legitimately over both urban and rural areas? International Journal of Health Geographics, 13(1), 22.

Boarini, R., \& Mira d'Ercole, M. (2006). Measures of material deprivation in OECD Countries. OECD social employment and migration, Working Papers, No. 37, Sussex, OECD Publishing.

Bond Huie, S. A., Krueger, P. M., Rogers, R. G., \& Hummer, R. A. (2003). Wealth, race and mortality. Social Science Quarterly, 84(3), 667-684.

Boyle, P., Gatrell, A., \& Duke-Williams, O. (1999). The effect on morbidity of variability in deprivation and population stability in England and Wales: An investigation at small-area level. Social Science and Medicine, 49(6), 791-799.

Boyle, P., Norman, P., \& Popham, F. (2009). Social mobility: Evidence that it can widen health inequalities. Social Science and Medicine, 68(10), 1835-1842. 
Burrows, S., Auger, N., Roy, M., \& Alix, C. (2010). Socio-economic inequalities in suicide attempts and suicide mortality in Quebec, Canada, 1990-2005. Public Health, 124(2), 78-85.

Cadum, E., Costa, F., Biggeri, A., \& Martuzzi, M. (1999). Deprivazione e mortalità: Un indice di deprivazione per l'analisi delle disuguaglianze su base geografica. Epidemiologia e Prevenzione, 23(3), 175187.

Caranci, N., Biggeri, A., Grisotto, L., Pacelli, B., Spadea, T., \& Costa, G. (2010). The Italian deprivation index at census block level: Definition, description and association with general mortality. Epidemiologia e Prevenzione, 34(4), 167-176.

Carstairs, V., \& Morris, R. (1991). Deprivation and health in Scotland. Aberdeen: Aberdeen University Press.

Davey Smith, G., Whitley, E., Dorling, D., \& Gunnel, D. (2001). Area based measures of social and economic circumstances: Cause specific mortality patterns depend on the choice of index. Journal of Epidemiology and Community Health, 55(2), 149-150.

De Muro, P., Mazziotta, M., \& Pareto, A. (2007). Composite indices for multidimensional development and poverty: An application to MDG indicators. Wye City Group Meeting, Rome, Italy. http://www.fao. org/es/ess/rural/wye_city_group.

Deaton, A., \& Lubotsky, D. (2003). Mortality, inequality and race in American cities and states. Social Science and Medicine, 56(6), 1139-1153.

Exeter, D. J., Boyle, P. J., \& Norman, P. (2011). Deprivation (im)mobility and cause-specific premature mortality in Scotland. Social Science and Medicine, 72(3), 389-397.

Exeter, D. J., Feng, Z., Flowerdew, R., \& Boyle, P. J. (2005). Shrinking areas and mortality: An artefact of deprivation effects? Journal of Epidemiology and Community Health, 59(11), 924-926.

Forrest, R., \& Gordon, D. (1993). People and places: A 1991 Census atlas of England. Bristol: University of Bristol, SAUS.

Friedman, M. (1937). The use of ranks to avoid the assumption of normality implicit in the analysis of variance. Journal of the American Statistical Association, 32(200), 675-701.

Gilthorpe, M. S., \& Wilson, R. C. (2003). Rural/urban differences in the association between deprivation and healthcare utilisation. Social Science and Medicine, 57(11), 2055-2063.

Gotsens, M., Mari-Del'Olmo, M., Perez, K., et al. (2013). Socioeconomic inequalities in injury mortality in small areas of 15 European cities. Health \& Place, 24, 165-177.

Gregory, I. N. (2002). The accuracy of areal interpolation techniques: Standardising 19th and 20th century census data to allow long-term comparisons. Computers, Environment and Urban Systems, 26(4), 293314.

Hagedoorn, P., Vandenheede, H., Vanthomme, K., Willaert, D., \& Gadeyne, S. (2016). A cohort study into head and neck cancer mortality in Belgium (2001-11): Are individual socioeconomic differences conditional on area deprivation? Oral Oncology, 61, 76-82.

Hartigan, J. A., \& Wong, M. A. (1979). Algorithm AS136: A K-means clustering algorithm. Journal of the Royal Statistical Society: Series C (Applied Statistics), 28(1), 100-108.

Havard, S., Deguen, S., Bodin, J., Louis, K., Laurent, O., \& Bard, D. (2008). A small-area index of socioeconomic deprivation to capture health inequalities in France. Social Science and Medicine, 67 (12), 2007-2016.

Haynes, R., Gale, S., Lovett, A., \& Bentham, G. (1996). Unemployment rate as an updatable health needs indicator for small areas. Journal of Public Health Medicine, 18(1), 27-32.

Hoffmann, R., et al. (2014). Social differences in avoidable mortality between small areas of 15 European cities: An ecological study. International Journal of Health Geographics, 13(1), 8.

Ivaldi, E., \& Testi, A. (2011). Genoa index of deprivation (GDI): An index of material deprivation for geographical areas. In C. M. Baird (Ed.), Social indicators: Statistics, trends and policy development. Hauppauge, New York: Nova Science Publishers.

Ivaldi, E., Bonatti, G, \& Soliani, G. (2017). An indicator for the measurement of political participation: The case of Italy. Social Indicator Research, 132(2), 605-620.

Jackson, C., Jones, M., \& Mishra, G. D. (2014). Educational and homeownership inequalities in stroke incidence: A population-based longitudinal study of mid-aged women. The European Journal of Public Health, 24(2), 231-236.

Jarman, B. (1983). Identification of underprivileged areas. British Medical Journal, 286(6385), 1705-1709.

Kelleher, C., Timoney, A., Friel, S., \& McKeown, D. (2002). Indicators of deprivation, voting patterns and health status at area level in the Republic of Ireland. Journal of Epidemiology and Community Health, 56(1), 36-44.

Lalloué, B., Monnez, J. M., Padilla, C., Kihal, W., Le Meur, N., Zmirou-Navier, D., et al. (2013). A statistical procedure to create a neighborhood socioeconomic index for health inequalities analysis. International Journal for Equity in Health, 12(1), 21. 
Mackenbach, J. P. (2010). Has the English strategy to reduce health inequalities failed? Social Science and Medicine, 71(7), 1249-1253.

Mackenbach, J. P. (2012). The persistence of health inequalities in modern welfare states: The explanation of a paradox. Social Science and Medicine, 75(4), 761-769.

Mackenbach, J. P., Bos, V., Andersen, O., Cardano, M., Costa, G., Harding, S., et al. (2003). Widening socioeconomic inequalities in mortality in six Western European countries. International Journal of Epidemiologic, 32(5), 830-837.

Mackenbach, J. P., Stirbu, I., Roskam, A. J., et al. (2008). Socioeconomic inequalities in health in 22 European countries. New England Journal of Medicine, 358(23), 2468-2481.

Mazziotta, C., Mazziotta, M., Pareto, A., \& Vidoli, F. (2010a). La sintesi di indicatori territoriali di dotazione infrastrutturale: Metodi di costruzione e procedure di ponderazione a confronto. Rivista di Economia e Statistica del Territorio, 1, 1-33.

Mazziotta, M., \& Pareto, A. (2007). Un indicatore sintetico di dotazione infrastrutturale: il metodo delle penalita' per coefficiente di variazione. In Lo sviluppo regionale nell'Unione Europea-Obiettivi, strategie, politiche. Atti della XXVIII Conferenza Italiana di Scienze Regionali, AISRe, Bolzano.

Mazziotta, M., \& Pareto, A. (2011). Un indice sintetico non compensativo per la misura della dotazione infrastrutturale: Un'applicazione in ambito sanitario. Rivista di Statistica Ufficiale, 13(1), 63-79.

Mazziotta, M., \& Pareto, A. (2012). A non-compensatory approach for the measurement of the quality of life. In F. Maggino \& G. Nuvolati (Eds.), Quality of life in Italy. Social Indicator Research Series 48 (pp. 27-40). Dordrecht: Springer.

Mazziotta, M., Pareto, A., \& Talucci, V. (2010b). La costruzione di indicatori di disuguaglianza sociale: Il caso delle regioni italiane. XXXI Conferenza Italiana di Scienze Regionali. http://www. grupposervizioambiente.it/aisre_sito/doc/papers/Mazziotta_Pareto_Talucci_AISRE.pdf.

Mishra, S. K. (2012). A note on the indeterminacy and arbitrariness of Pena's method of construction of synthetic indicator. SSRN. http://ssrn.com/abstract=2026293.

Montero, J. M., Chasco, C., \& Larraz, B. (2010). Building an environmental quality index for a big city: A spatial interpolation approach combined with a distance indicator. Journal of Geographical Systems, 12 (4), 435-459.

Munda, G., \& Nardo, M. (2005). Non-compensatory composite indicators for ranking countries: A defensible setting (p. 21833). EUR: EUR Report.

Nardo, M., Saisana, M., Saltelli, A., Tarantola, S., Hoffman, A., \& Giovannini, E. (2005). Handbook on constructing composite indicators: Methodology and user guide. Paris: OECD Publishing.

Nayak, P. \& Mishra, S. K. (2012). Efficiency of Pena's P2 distance in construction of human development indices. MPRA-Munich Personal RePEc Archive, Paper 39022.

Noble, M., Barnes, H., Wright, G., \& Roberts, B. (2010). Small area indices of multiple deprivation in South Africa. Social Indicators Research, 95(2), 281-297.

Norman, P. (2010). Identifying change over time in small area socio-economic deprivation. Applied Spatial Analysis and Policy, 3(2-3), 107-138.

Norman, P., Gregory, I., Dorling, D., \& Baker, A. (2008). Geographical trends in infant mortality: England and Wales, 1970-2006. Health Statistics Quarterly, 40, 18-29.

O'Reilly, G., O'Reilly, D., Rosato, M., \& Connolly, S. (2007). Urban and rural variations in morbidity and mortality in Northern Ireland. BMC Public Health, 7(1), 123.

Panczak, R., Galobardes, B., Voorpostel, M., Spoerri, A., Zwahlen, M., \& Egger, M. (2012). A Swiss neighbourhood index of socioeconomic position: Development and association with mortality. Journal of Epidemiology and Community Health, 66(12), 1129-1136.

Peña, J. B. (1977). Problemas de la medicio'n del bienestar y conceptos afines (Una aplicacio'n al caso espanol). Madrid: Instituto Nacional de Estadı'stica (INE).

Petrelli, A., Gnavi, R., Marinacci, C., \& Costa, G. (2006). Socioeconomic inequalities in coronary heart disease in Italy: A multilevel population-based study. Social Science and Medicine, 63(2), 446-456.

Regidor, E., Lostao, L., Pascual, C., Martínez, D., Calle, M. E., \& Domínguez, V. (2005). Income in large residential areas and premature mortality in six countries of the European Union. Health Policy, 75(1), 99-108.

Saisana, M., Saltelli, A., \& Tarantola, S. (2005). Uncertainty and sensitivity analysis techniques as tools for the quality assessment of composite indicators. Journal of the Royal Statistical Society: Series A (Statistics in Society), 168(2), 307-323.

Salzman, J. (2003). Methodological choices encountered in the construction of composite indices of economic and social well-being. Ottawa: Centre for the Study of Living Standards.

Santana, P., Costa, C., Marí-Dell'Olmo, M., Gotsens, M., \& Borrell, C. (2015). Mortality, material deprivation and urbanization: Exploring the social patterns of a metropolitan area. International Journal for Equity in Health, 14(1), 1-13. 
Schroeder, J. P. (2007). Target-density weighting interpolation and uncertainty evaluation for temporal analysis of census data. Geographical Analysis, 39(3), 311-335.

Sen, A. (1987). On ethics and economics. Oxford: Basil Blackwell.

Senior, M. L. (2002). Deprivation indicators. In P. Rees, D. Martin, \& P. Williamson (Eds.), The census data system (pp. 123-137). Chichester: Wiley.

Smits, J. P. J. M., Westert, G. P., \& Van Den Bos, G. A. M. (2002). Socioeconomic status of very small areas and stroke incidence in the Netherlands. Journal of Epidemiology and Community Health, 56(8), 637-640.

Somarriba, N., \& Pena, B. (2009). Synthetic indicators of quality of life in Europe. Social Indicators Research, 94(1), 115-133.

Spadea, T., Zengarini, N., Kunst, A., Zanetti, R., Rosso, S., \& Costa, G. (2010). Cancer risk in relationship to different indicators of adult socioeconomic position in Turin, Italy. Cancer Causes Control, 21(7), $1117-1130$.

Strand, B. H., Groholt, E. K., Steingrimmsdottir, O. A., Blakely, T., Graff-Iversen, S., \& Naess, O. (2010). Educational inequalities in mortality over four decades in Norway: Prospective study of middle aged men and women followed for cause specific mortality, 1960-2000. BMJ, 340, c654.

Stringhini, S., Sabia, S., Shipley, M., Brunner, E., Nabi, H., Kivimaki, M., et al. (2010). Association of socioeconomic position with health behaviors and mortality. JAMA, 303(12), 1159-1166.

Su, S., Gong, Y., Tan, B., Pi, J., Weng, M., \& Cai, Z. (2016). Area social deprivation and public health: Analyzing the spatial non-stationary associations using geographically weighed regression. Social Indicators Research. doi:10.1007/s11205-016-1390-6.

Testi, A., \& Ivaldi, E. (2009). Material versus social deprivation and health: A case study of an urban area. The European Journal of Health Economics, 10(3), 323.

Townsend, P. (1987). Deprivation. Journal of Social Policy, 16(2), 125-146.

Townsend, P., Phillimore, P., \& Beattie, A. (1988). Health and deprivation: Inequality and the North. London: Croom Helm.

Van Doorslaer, E. (1997). Socioeconomic inequalities in health: Measurement, computation and statistical inference. Journal of Econometrics, 77(1), 87-103. 